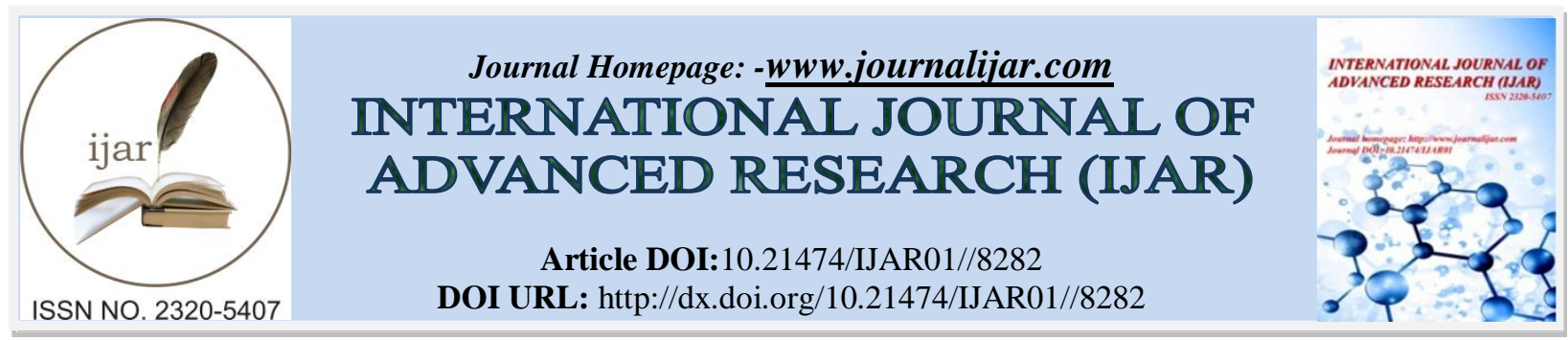

RESEARCH ARTICLE

\title{
IDENTIFYING POLYPHARMACY THROUGH PATIENT CONSULATION W GERIATRICS AT TERITARY CARE HOSPITAL
}

\section{P.V Praveena ${ }^{2}$, E. Akshitha ${ }^{1}$ and Salma Tasneem ${ }^{1}$}

1. Pharm D (Doctor of pharmacy), Department of Pharmacy Practice Sree Dattha institution of Pharmacy affiliated to Jawaharlal nehru technological intitution, Hyderabad - 500035, Telangana, India.

2. M Pharm, $(\mathrm{PhD})$. Associate professor, Department of Pharmacology,Sree Dattha institution of Pharmacy, affiliated to Jawaharlal nehru technological intitution, Hyderabad - 500006, Telangana, India.

\section{Manuscript Info}

Manuscript History

Received: 20 October 2018

Final Accepted: 22 November 2018

Published: December 2018

\section{Abstract}

Background:-The rapidly growing numbers and proportion of elderly meantthat more people will be entering a period of life where the risk of developing certain chronic and debilitating diseases is significantly higher.People over the age 6pyears are more likely to be on medication than younger people

Objective:-To determine the common drugs involved in Polypharmacy and resolve potentially inappropriate medications in geriatrics.

Materials \& Methods:-A prospective observation and non invasive study was carried out in the departments of general medicine, orthopedics,general surgery at teritory care hospital for duration of 6 months

Result:-A total of 105 cases of Polypharmacy were recorded from a total population of 10,000 Patients,among which males 71 cases $(35 \%)$,females 34 cases $(15 \%)$, maximum Patients belong to age group of 60-70age i.e 56cases,71-80age were 20 cases,more than 80age was 19 cases.Most of the cases collected from general medicines i.e 56cases, general surgery i.e 18cases, orthopedics

Conclusion:- Polypharmacy and inappropriate drug use is prevalent among the elderly. In our study, Polypharmacy is involved more in cardiovascular diseases and surgery. Inappropriate drugs like aspirin, nifidipine, spironolactone, dicoflenac aresignificant. So, while prescribing drugs to elderly Beer's criteria and STOPP/START criteria should be considered as a standard guideline. Copy Right, IJAR, 2017,. All rights reserved.

\section{Introduction:-}

The rapidly growing numbers and proportion of elderly mean that more people will be entering a period of life where the risk of developing certain chronic and debilitating disease is significantly higher. People over the age of 60 years are more likely to be on medication than younger people. They are often taking several drugs at once to treat concomitant disease processes.

Corresponding Author:-E.Akshitha.

Address:- Pharm D (Doctor of pharmacy ),Department of Pharmacy Practice Sree Dattha institution of Pharmacy affiliated to Jawaharlal nehru technological intitution, Hyderabad - 500035, Telangana, India. 
According to the WHO Polypharmacy is defined as "the administration of many drugs at the same time or the administration of an excessive number of drugs". Generally use of 5 or more drugs is considered as Polypharmacy.

There may be many consequences associated with the Polypharmacy.Patients are at increased risk of receiving an inappropriate medication and having an adverse drug reaction, which may impact patients adherence to his/her medication regimen.It has also been associated with the increased risk of morbidity or mortality.

The unnecessary drug therapy problems frequently tend to be overlooked in Polypharmacy prescribing. Drug therapy is considered unnecessary for the patient if there is no longer valid medical indication of a particular drug. Unnecessary drug therapy can arise from several common causes, including the following:

No medical indication, prescribing medication that is contraindicated in patients, prescribing unfavourable choice of medicine, dose or duration.

Polypharmacy is known to increase the risk of adverse drug reaction (ADR), drug-drug and drug-disease interaction it has been claimed that $13 \%$ risk of adverse drug interactions, rising to $38 \%$ when taking four drugs and $82 \%$ if seven or more drugs are given simultaneously.

Polypharmacy creates complex medication regimen that make non-adherence a common problem in elderly, with prevalence rates averaging $50 \%$.

Polypharmacy also makes compliance with medications more challenging. Non-compliance with prescribed medications can result in sub-optimal therapeutic effectiveness and can have major clinical consequences. If the existence of non-compliance is not recognised, the physician may increase the dose of the initial medication or add a second agent, increasing both the risk and the cost of treatment.

The universally accepted screening tools for identifying the potentially inappropriate medications include Beers Criteria, START/STOPP Criteria.

For more than 20 years, the Beers Criteria for Potentially Inappropriate Medication Use in Older Adults has been the leading source of information about the safety of prescribing drugs for older people. To help prevent medication side effects and other drug-related problems in older adults, the American Geriatrics Society (AGS) has updated and expanded this important resource.

START/STOPP Criteria provide explicit, evidence based rules of avoidance of commonly encountered instances of potentially inappropriate prescribing and potential prescribing omissions, improve medication appropriateness and prevent adverse drug events.

\section{Objectives:-}

1. To identify the common drugs involved in Polypharmacy.

2. To rule out the disease in which Polypharmacy is involved.

3. To identify and resolve potentially inappropriate medications in geriatrics.

4. To find out the consequences of Polypharmacy like side effects, adverse drug reactions, drug-drug interactions.

\section{Methodology:-}

1. Study site: In-patient and Out-patient departments of general medicine, orthopaedics, general surgery, in Aware Global hospital.

2. Study design: A Prospective Observational study.

3. Study duration: 6 months.

\section{Inclusion criteria:-}

1. Patient of either sex as inpatients and outpatients attending departments of General medicine, Orthopaedics, General surgery.

2. Patients more than 60 years of age. 


\section{Exclusion Criteria:-}

1. Tuberculosis patients, HIV patients, Psychiatric patients.

2. Patients with severe organ failure.

3. Cases from emergency departments.

\section{Results:-}

A total of 105 cases have been collected in the departments like General Medicine, General Surgery, Orthopaedics, Gastroenterology.

\section{Age wise distrubtion of Polypharmacy}

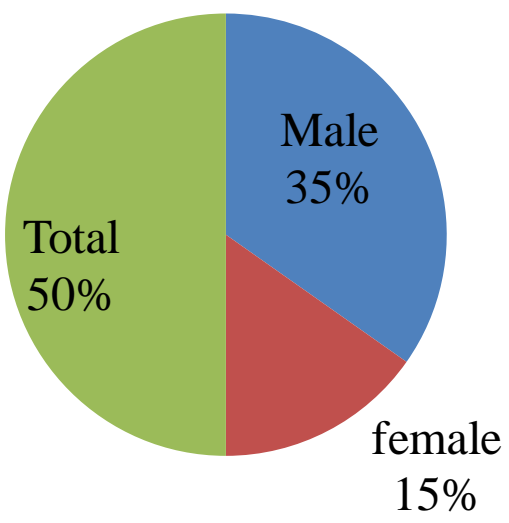

AGE:-

\begin{tabular}{|l|c|c|c|c|c|c|c|c|}
\hline $\begin{array}{l}\text { Source of } \\
\text { variations }\end{array}$ & df & $\begin{array}{c}\text { Sum of } \\
\text { squares }\end{array}$ & $\begin{array}{c}\text { Mean } \\
\text { Squares }\end{array}$ & F Ratio & Probability & $\pi^{2}$ & $\mathbf{n p}^{2}$ & $\mathbf{0}^{2}$ \\
\hline BetweenGroups & $\mathbf{1}$ & $\mathbf{0 . 1 5 6 2 4}$ & $\mathbf{0 . 1 5 6 2 4}$ & $\mathbf{0 . 2 3 8}$ & $\mathbf{0 . 6 2 6 8 9}$ & $\mathbf{0 . 0 0 2}$ & $\mathbf{0 . 0 0 2}$ & $\mathbf{- 0 . 0 0 7}$ \\
Within Groups & $\mathbf{1 0 3}$ & $\mathbf{6 7 . 6 9 1 3 8}$ & $\mathbf{0 . 6 6 7 2 0}$ & & & & & \\
Total & $\mathbf{1 0 4}$ & $\mathbf{6 7 . 8 4 7 6 2}$ & $\mathbf{0 . 6 5 2 3 8}$ & & & & & \\
\hline
\end{tabular}

\section{Frequency Distribution}

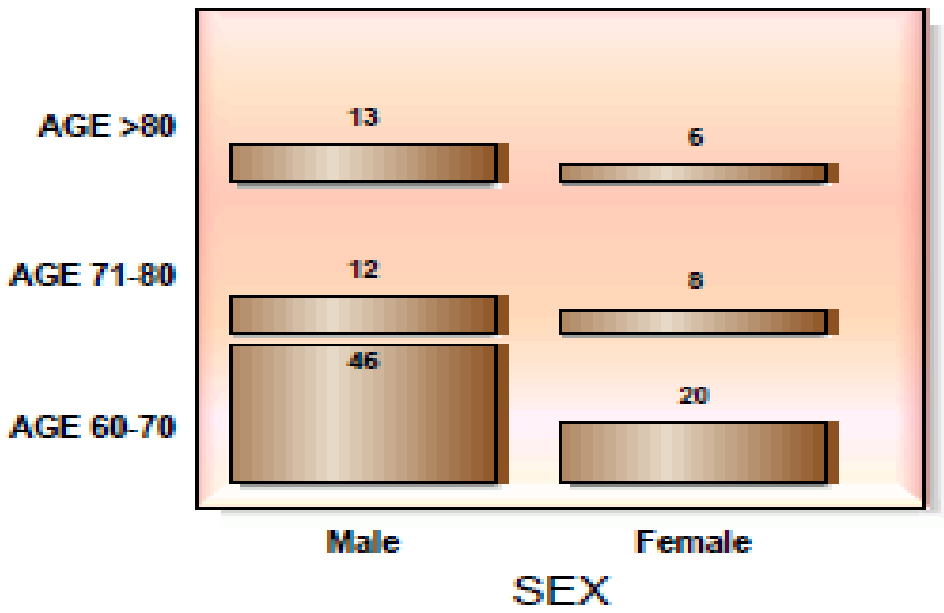




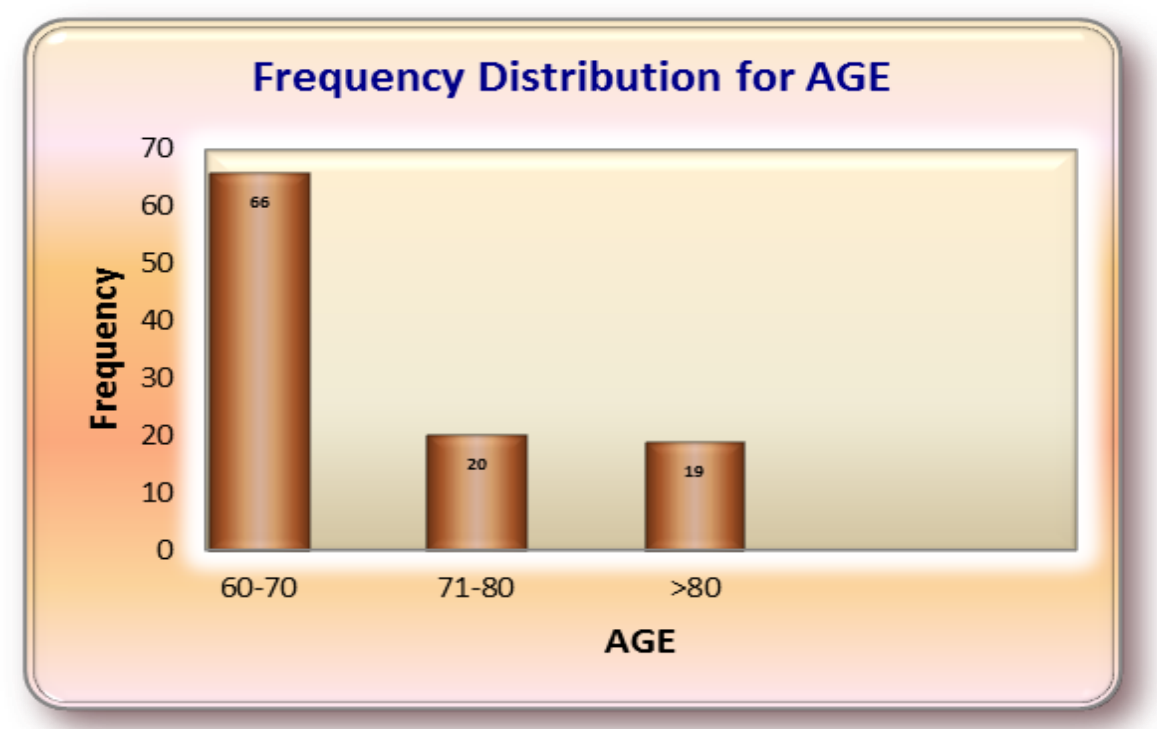

Gender:-

Gender wise distribution of Polypharmacy:

\begin{tabular}{|l|l|l|c|c|l|}
\hline Source of variation & df & Sum of squares & Mean Squares & F Ratio & Probability \\
\hline Between Samples & 2.000 & 0.146 & 0.073 & 0.326 & 0.723 \\
\hline Within Samples & 102.000 & 22.846 & 0.224 & & \\
\hline
\end{tabular}

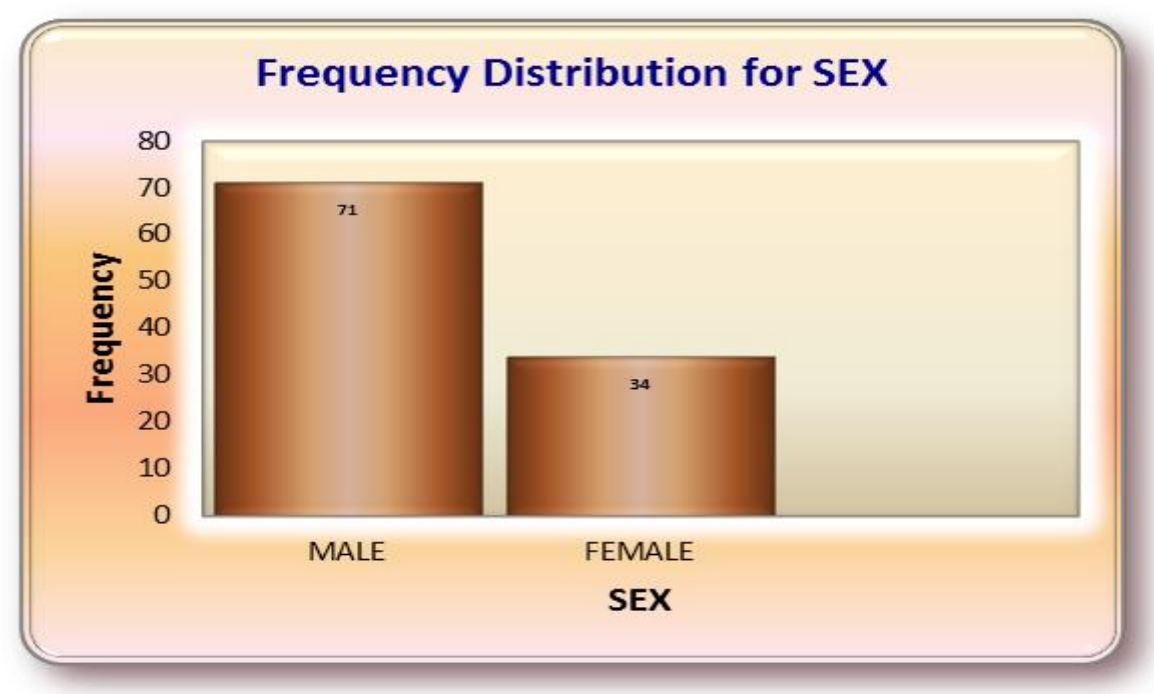

Department wise distribution of Polypharmacy:

Department:-

\begin{tabular}{|l|l|l|l|l|l|}
\hline Source of variation & df & Sum of squares & Mean Squares & F Ratio & Probability \\
\hline Between Samples & 2.000 & 6.273 & 3.136 & 2.703 & 0.072 \\
\hline Within Samples & 102.000 & 118.356 & 1.160 & & \\
\hline
\end{tabular}




\section{Frequency Distribution}
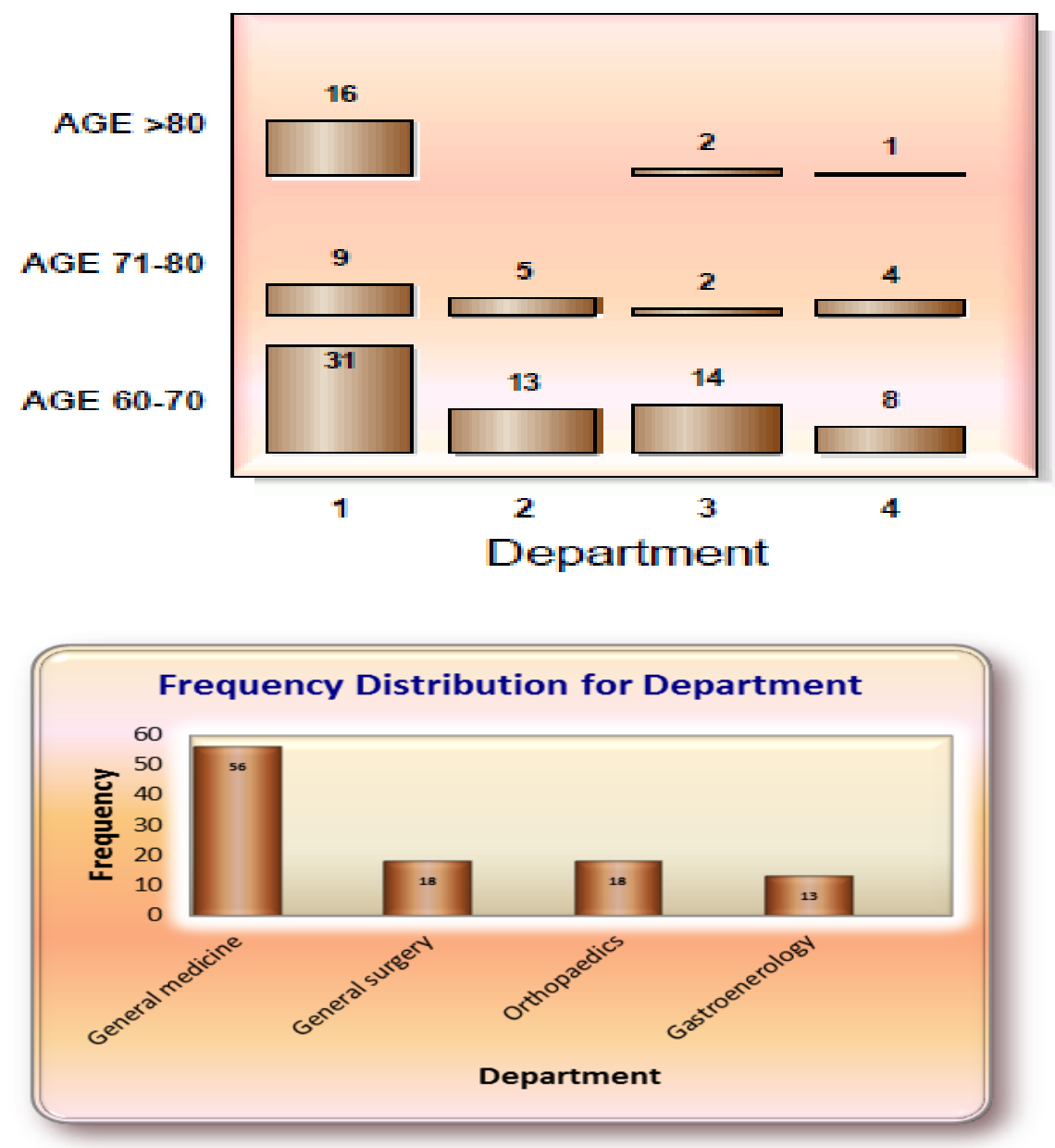

Pantop:-

\begin{tabular}{|l|l|l|c|c|l|}
\hline Source of variation & df & Sum of squares & Mean Squares & F Ratio & Probability \\
\hline Between Samples & 2.000 & 1.275 & 0.638 & 3.897 & 0.023 \\
\hline Within Samples & 102.000 & 16.687 & 0.164 & & \\
\hline
\end{tabular}

\section{Frequency Distribution}

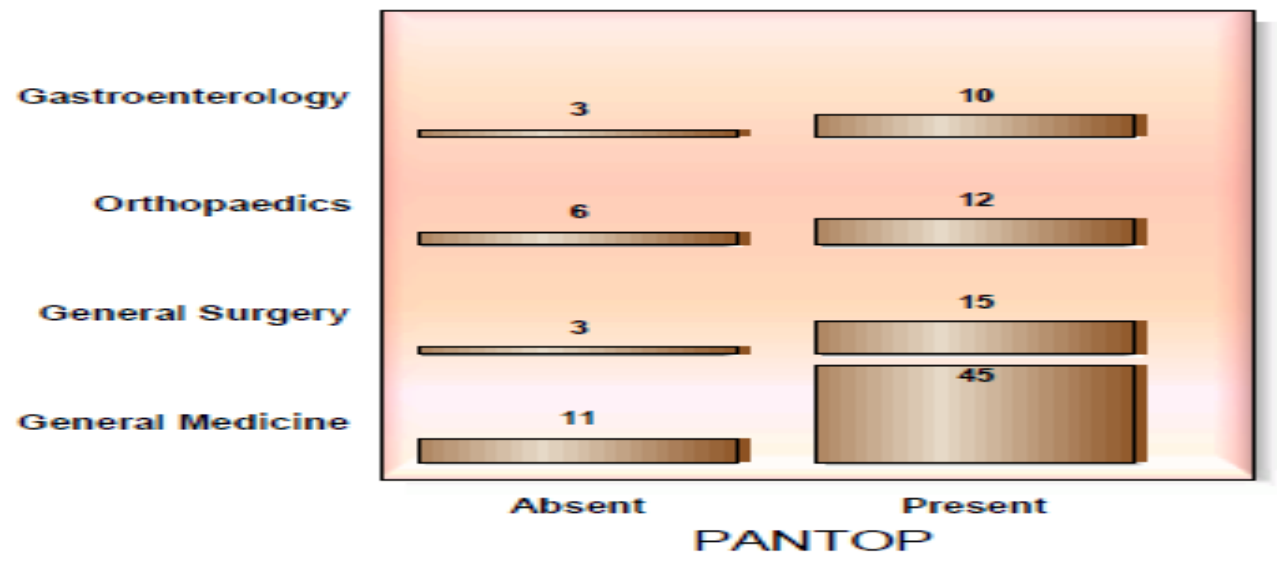




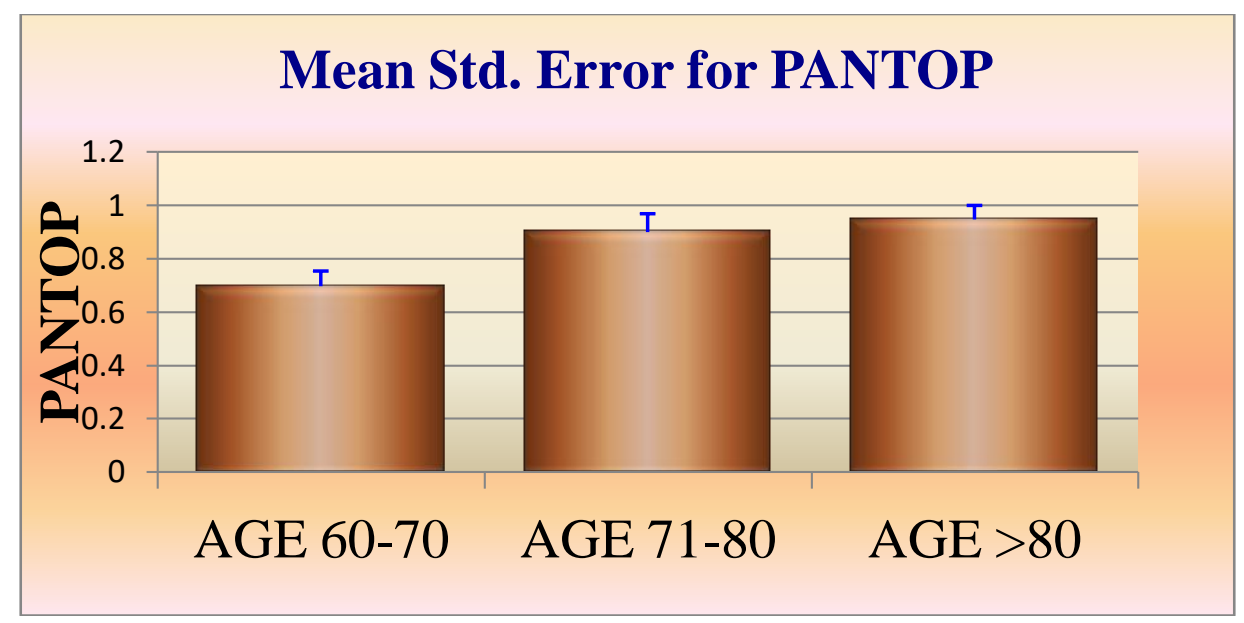

Nicardipine:-

\begin{tabular}{|l|l|c|c|l|l|}
\hline Source of variation & df & Sum of squares & Mean Squares & F Ratio & Probability \\
\hline Between Samples & 2.000 & 0.475 & 0.238 & 3.503 & 0.034 \\
\hline Within Samples & 102.000 & 6.915 & 0.068 & & \\
\hline
\end{tabular}

Frequency Distribution
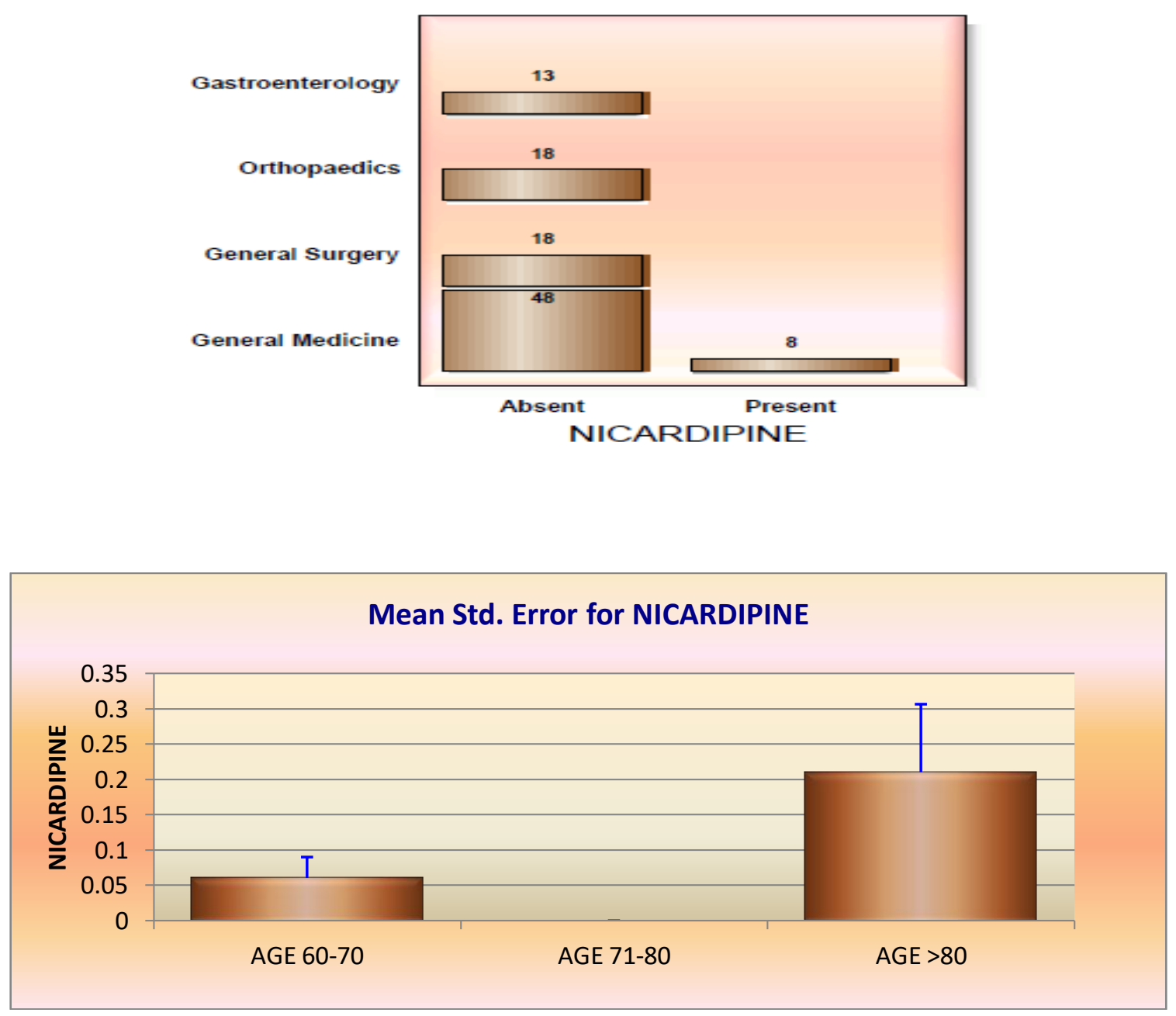
Mannitol:-

\begin{tabular}{|l|l|l|c|c|l|}
\hline Source of variation & \multicolumn{1}{|c|}{$\mathrm{df}$} & Sum of squares & Mean Squares & F Ratio & Probability \\
\hline Between Samples & 2.000 & 0.564 & 0.282 & 5.652 & 0.005 \\
\hline Within Samples & 102.000 & 5.093 & 0.050 & & \\
\hline
\end{tabular}

Frequency Distribution
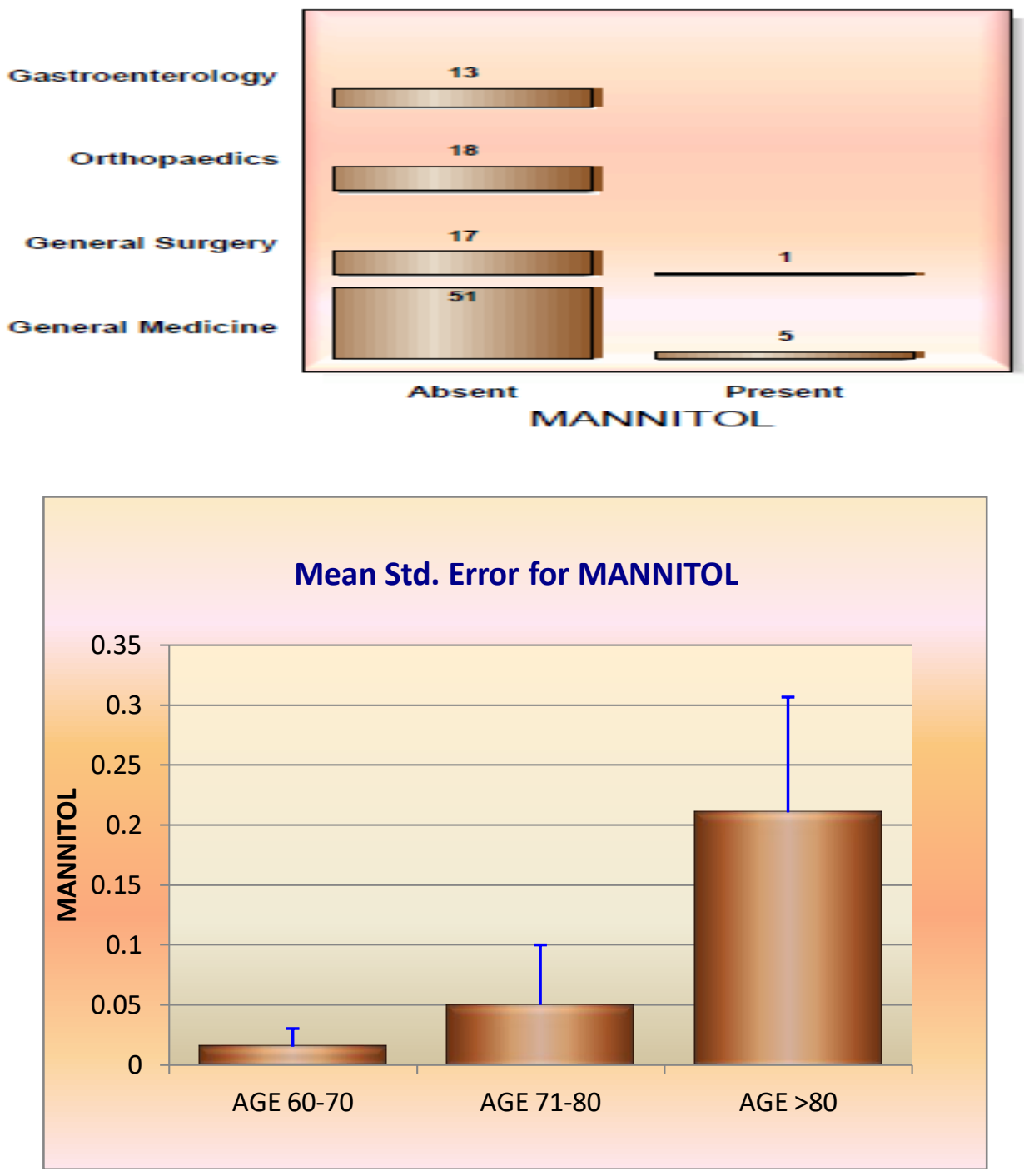


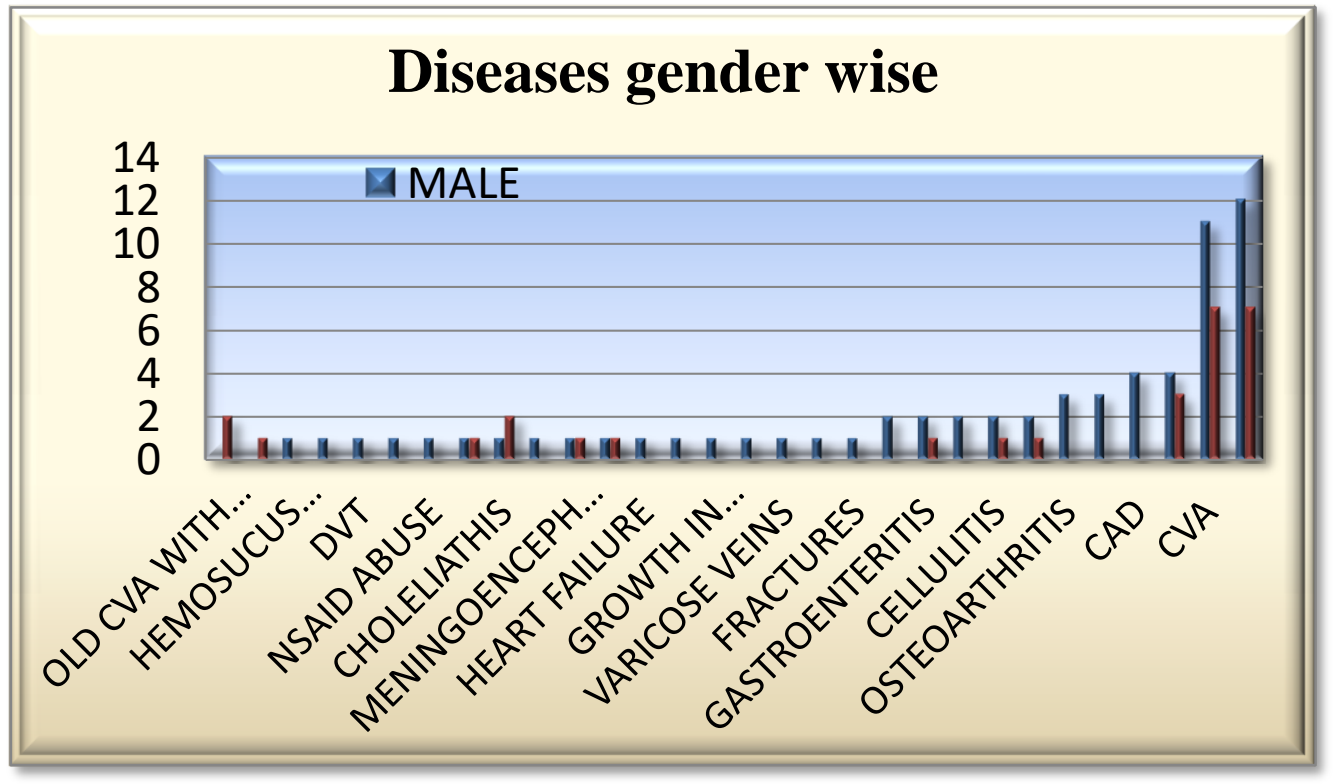

CVA:-

\begin{tabular}{|l|l|l|l|l|l|}
\hline Source of variation & df & Sum of squares & Mean Squares & F Ratio & Probability \\
\hline Between Samples & 3.000 & 2.13056 & 0.71019 & 5.611 & 0.005 \\
\hline Within Samples & 101.000 & 12.78373 & 0.12657 & & \\
\hline
\end{tabular}

Frequency Distribution
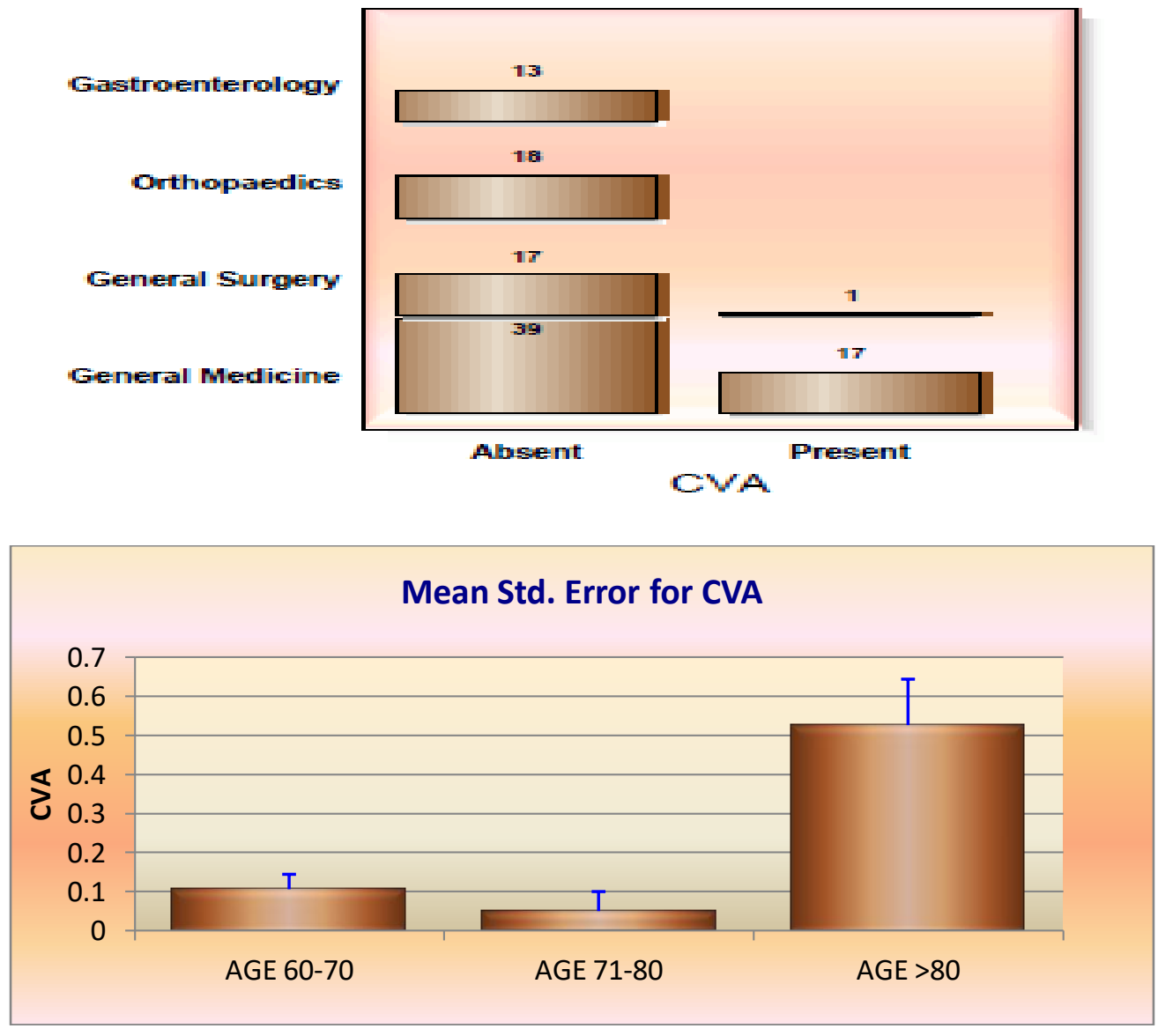
CAD:-

\begin{tabular}{|l|l|l|c|c|l|}
\hline Source of variation & df & Sum of squares & Mean Squares & F Ratio & Probability \\
\hline Between Samples & 3.000 & 0.36548 & 0.12183 & 3.534 & 0.01749 \\
\hline Within Samples & 101.000 & 3.48214 & 0.03448 & & \\
\hline
\end{tabular}

\section{Frequency Distribution}
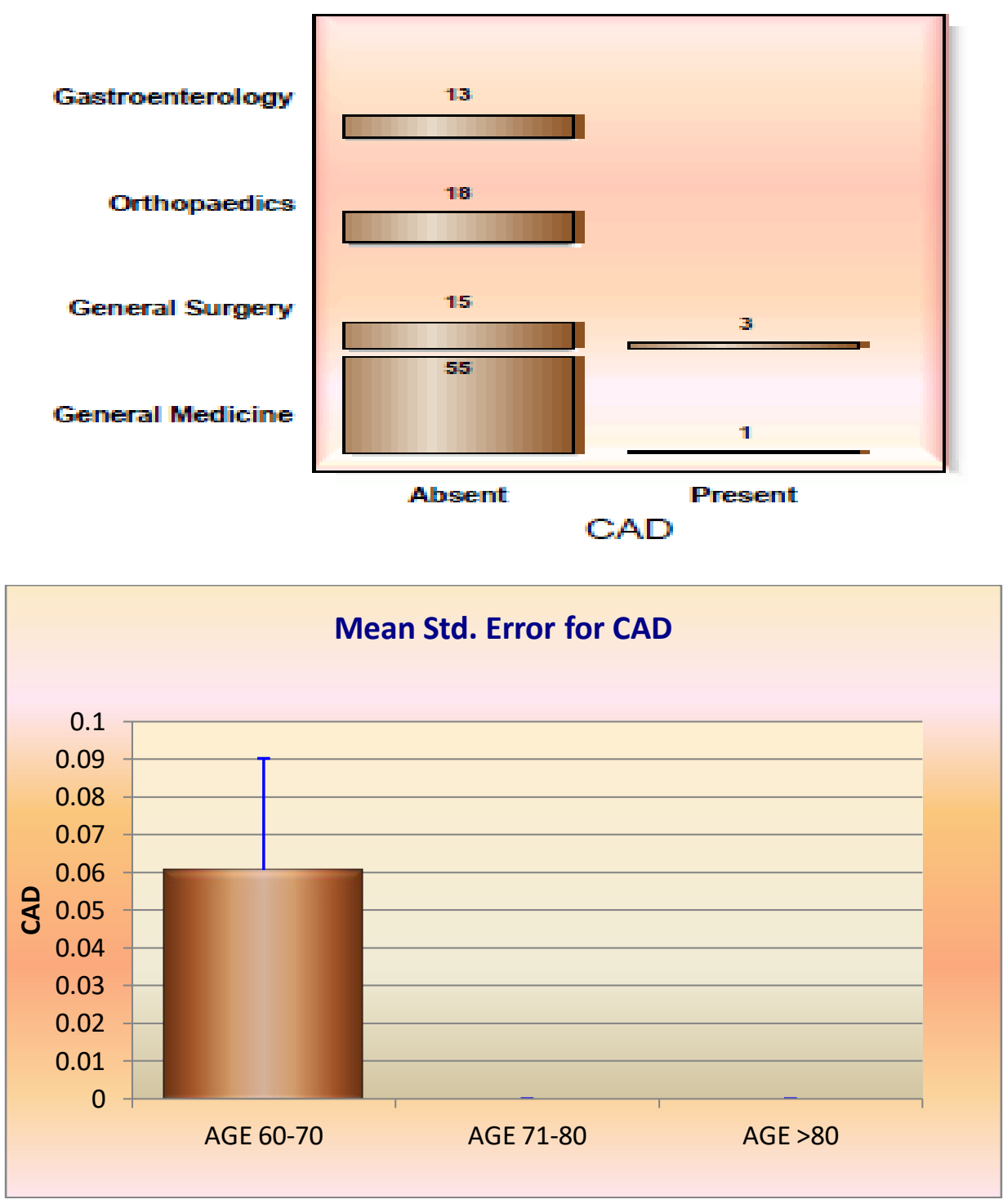

Diabetic Foot With Cad:-

\begin{tabular}{|l|l|c|c|c|l|}
\hline Source of variation & \multicolumn{1}{|c|}{ df } & Sum of squares & Mean Squares & F Ratio & Probability \\
\hline Between Samples & 3 & 0.18413 & 0.06138 & 3.487 & 0.01855 \\
\hline Within Samples & 101 & 1.77778 & 0.01760 & & \\
\hline
\end{tabular}




\section{Frequency Distribution}
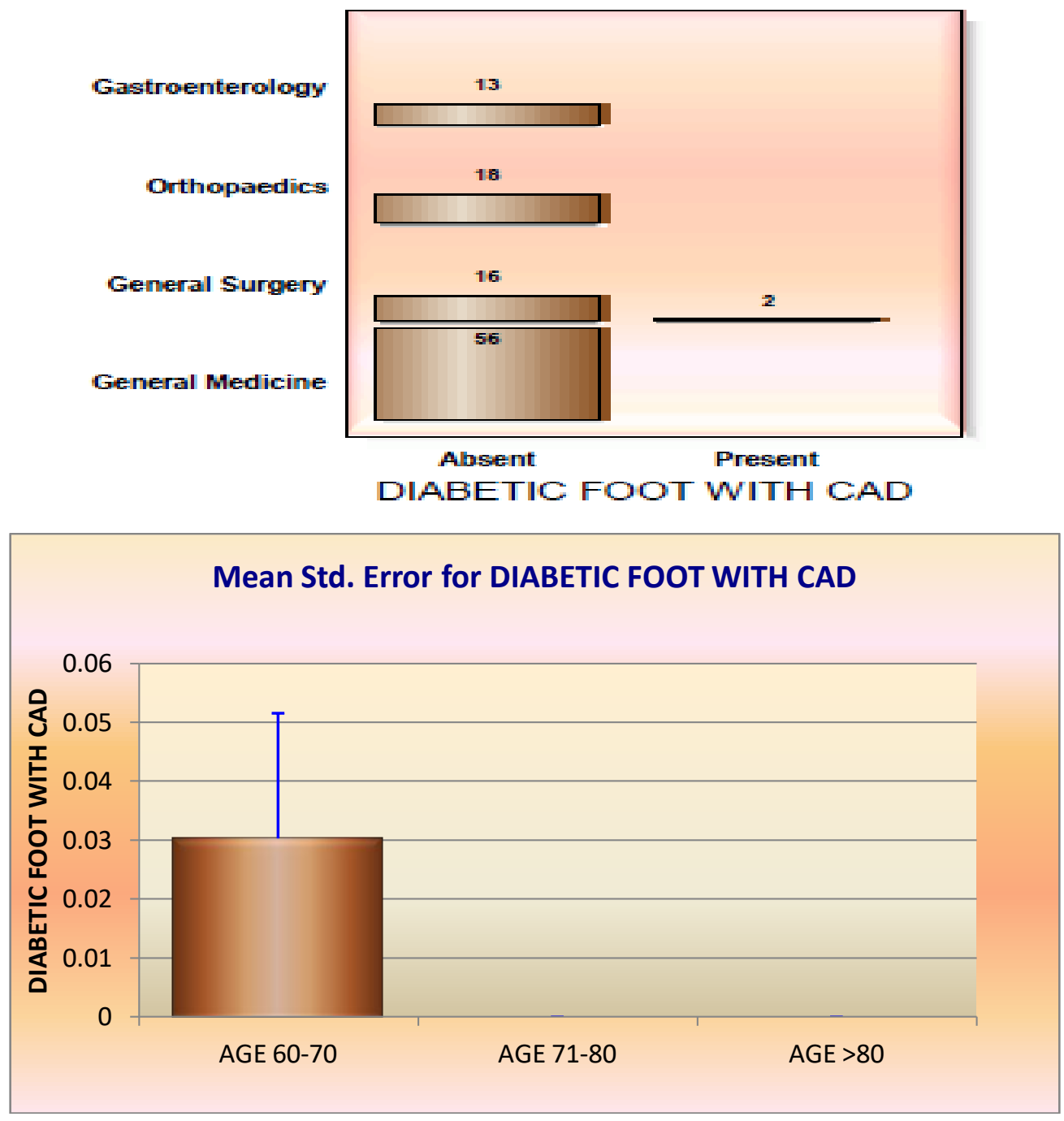

Choleliathis:-

\begin{tabular}{|l|l|l|c|c|l|}
\hline Source of variation & \multicolumn{1}{|c|}{ df } & Sum of squares & Mean Squares & F Ratio & Probability \\
\hline Between Samples & 3 & 0.27753 & 0.09251 & 3.544 & 0.01728 \\
\hline Within Samples & 101 & 2.63675 & 0.02611 & & \\
\hline
\end{tabular}




\section{Frequency Distribution}
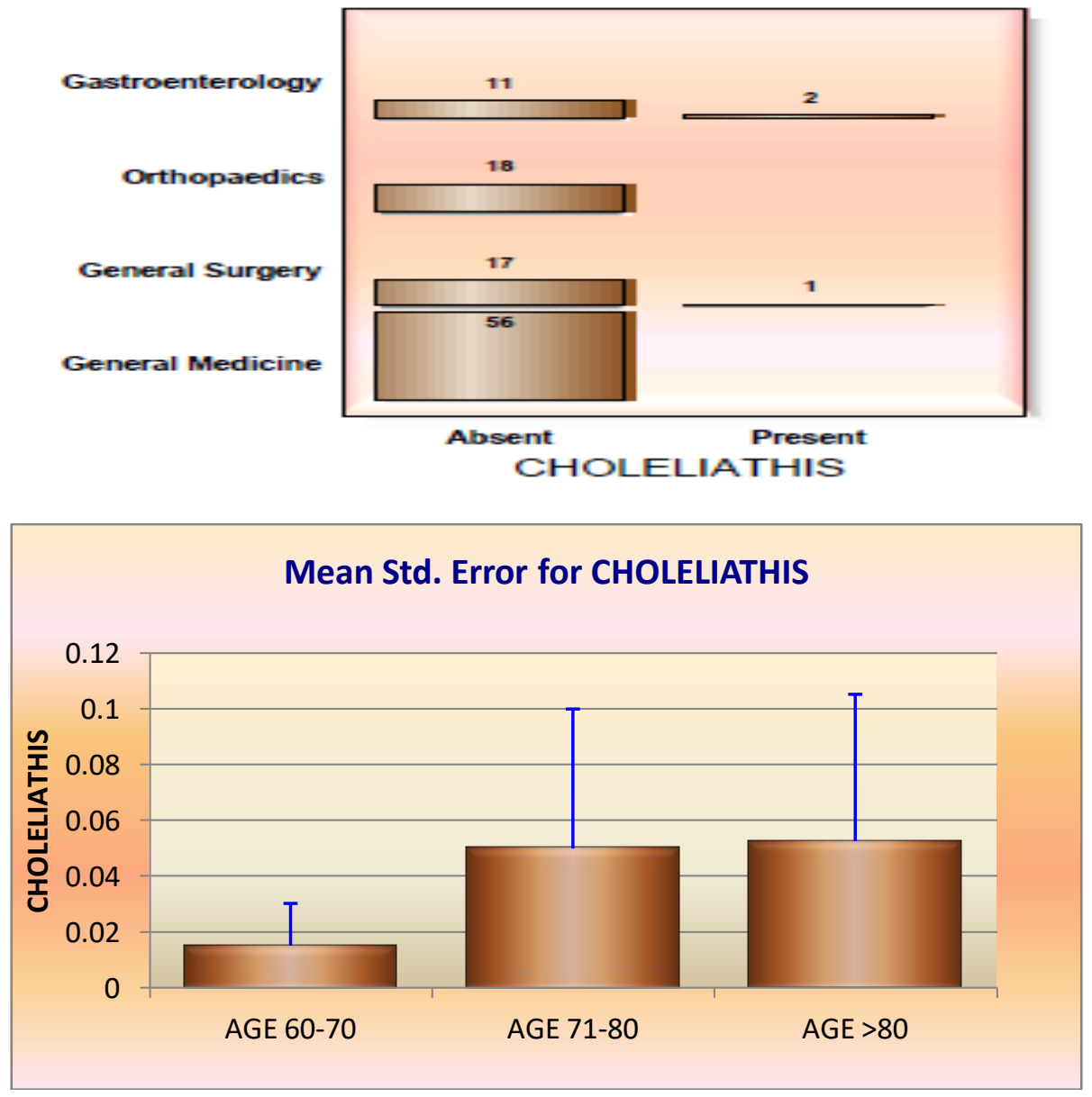

Traumatic Quadraperesis:-

\begin{tabular}{|l|l|c|c|c|l|}
\hline Source of variation & \multicolumn{1}{|c|}{ df } & Sum of squares & Mean Squares & F Ratio & Probability \\
\hline Between Samples & 3 & 0.18413 & 0.06138 & 3.487 & 0.01855 \\
\hline Within Samples & 101 & 1.77778 & 0.01760 & & \\
\hline
\end{tabular}

\section{Frequemoy Distribution}

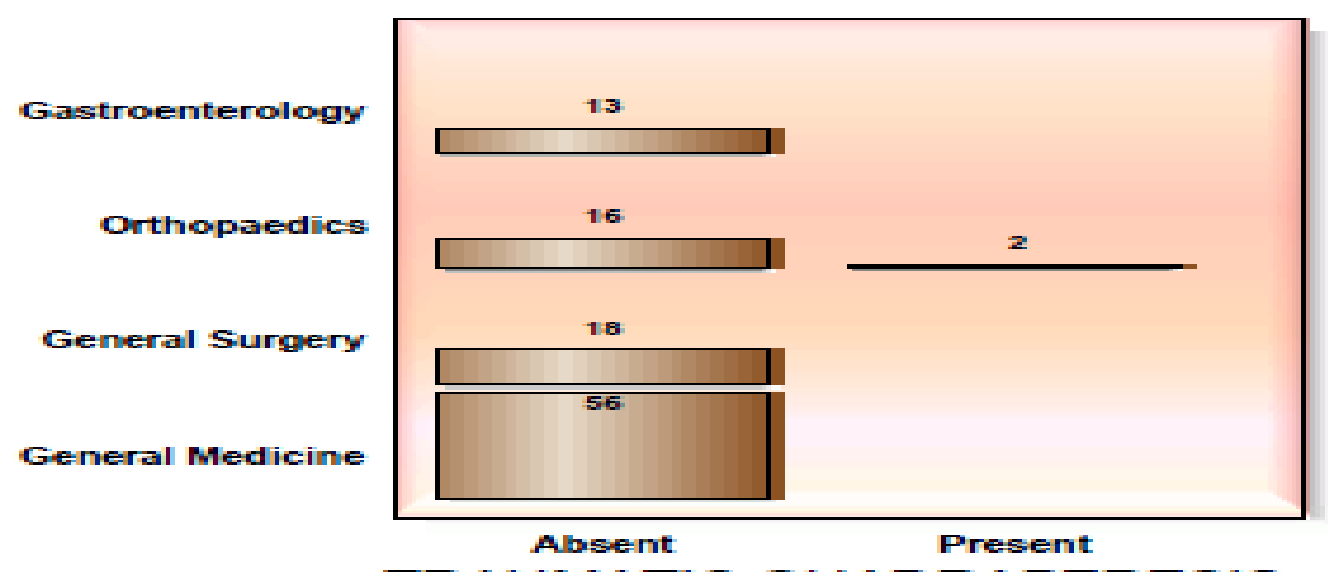

TRAUMATIC QUADRAPERESIS 


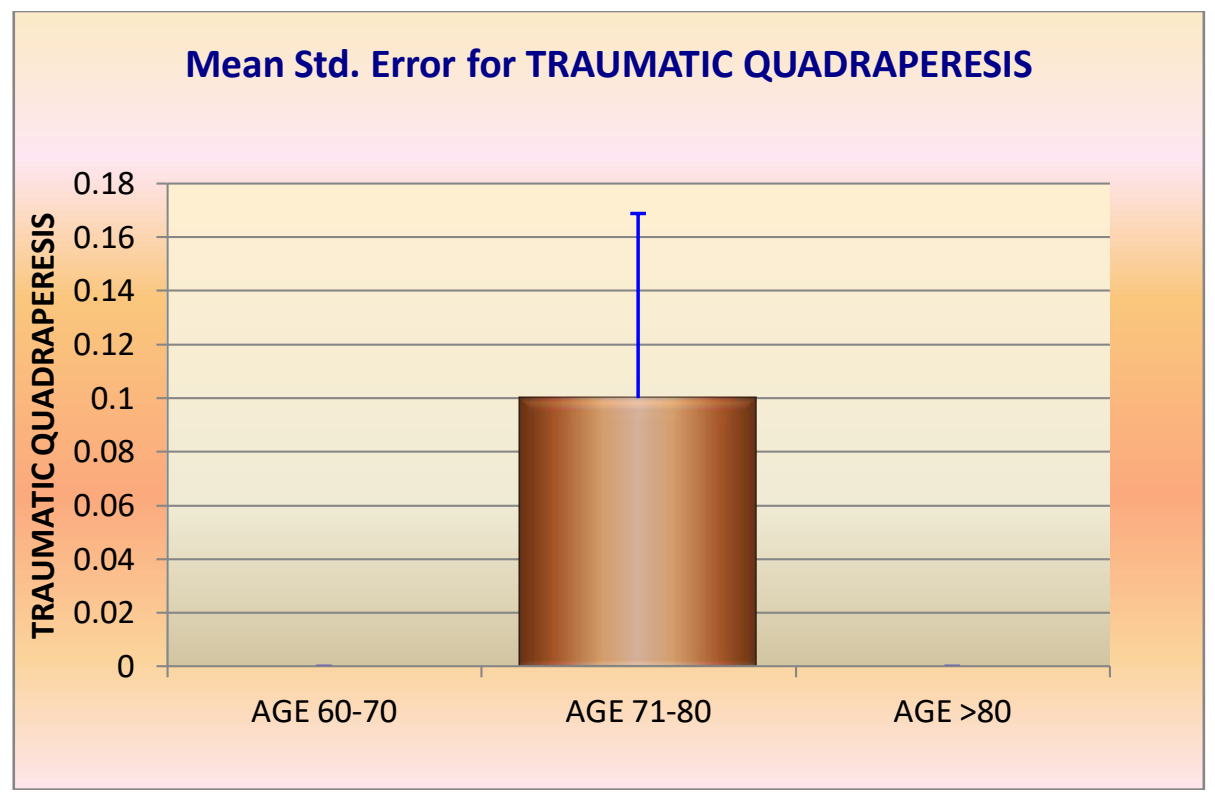

Osteoarthritis:-

\begin{tabular}{|l|l|l|c|l|l|}
\hline Source of variation & \multicolumn{1}{|c|}{$\mathrm{df}$} & Sum of squares & Mean Squares & F Ratio & Probability \\
\hline Between Samples & 3 & 0.41429 & 0.13810 & 5.579 & 0.00139 \\
\hline Within Samples & 101 & 2.50000 & 0.02475 & & \\
\hline
\end{tabular}

Frequency Distribution

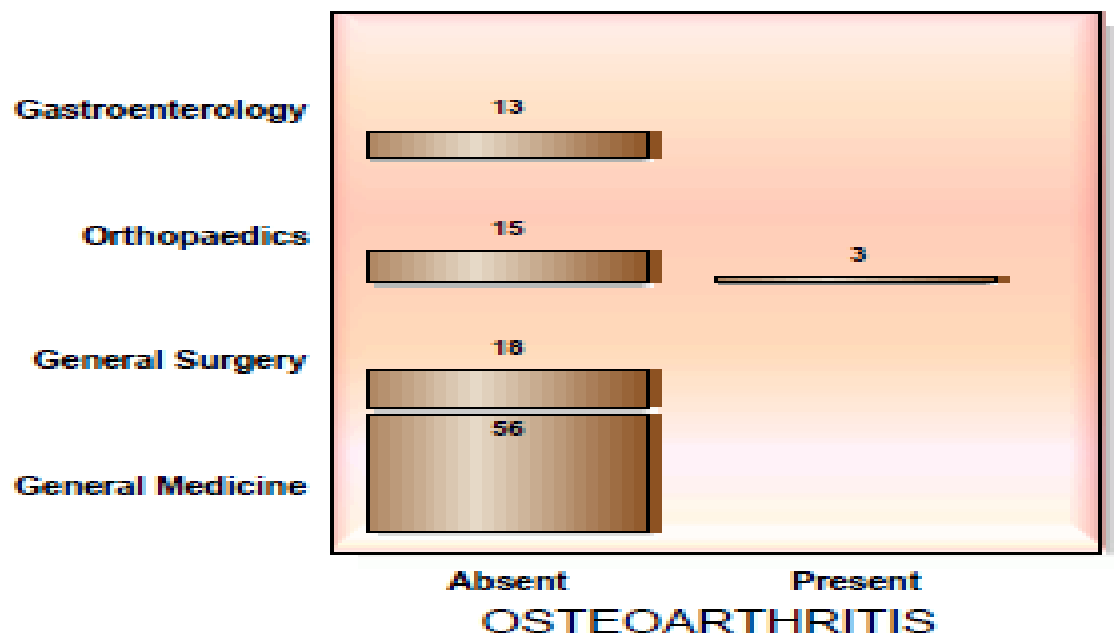




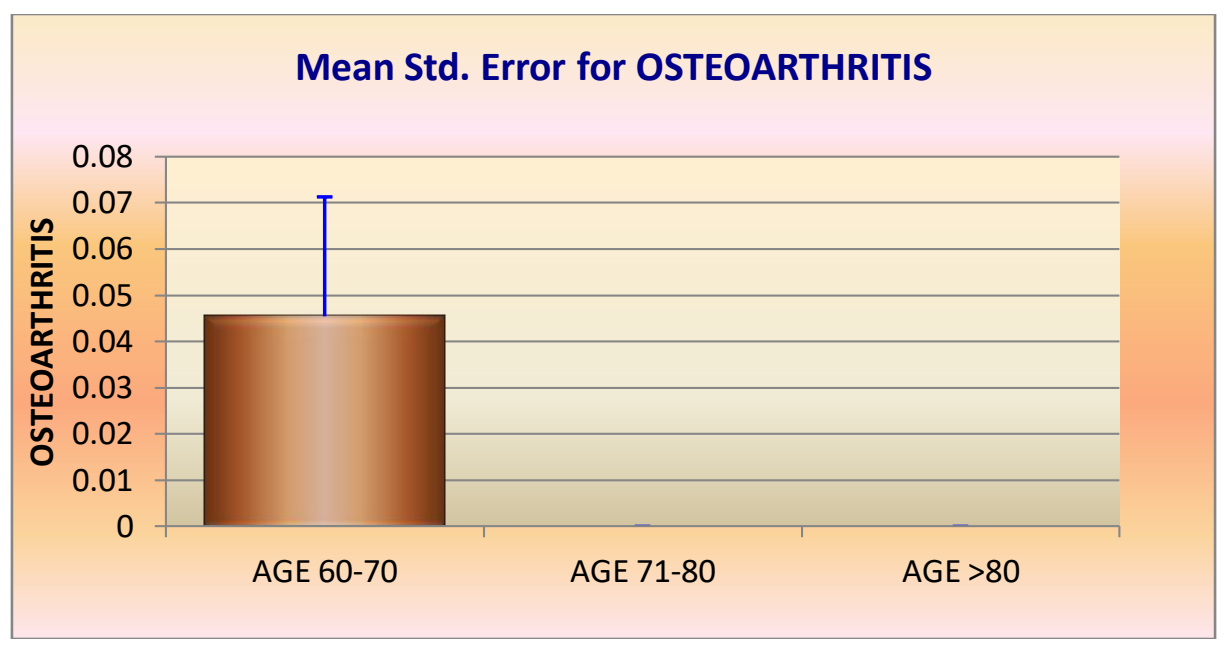

Cellulitis:-

\begin{tabular}{|l|l|c|c|c|l|}
\hline Source of variation & \multicolumn{1}{|c|}{ df } & Sum of squares & Mean Squares & F Ratio & Probability \\
\hline Between Samples & 3 & 0.41429 & 0.13810 & 5.579 & 0.00139 \\
\hline Within Samples & 101 & 2.50000 & 0.02475 & & \\
\hline
\end{tabular}

Frequency Distribution
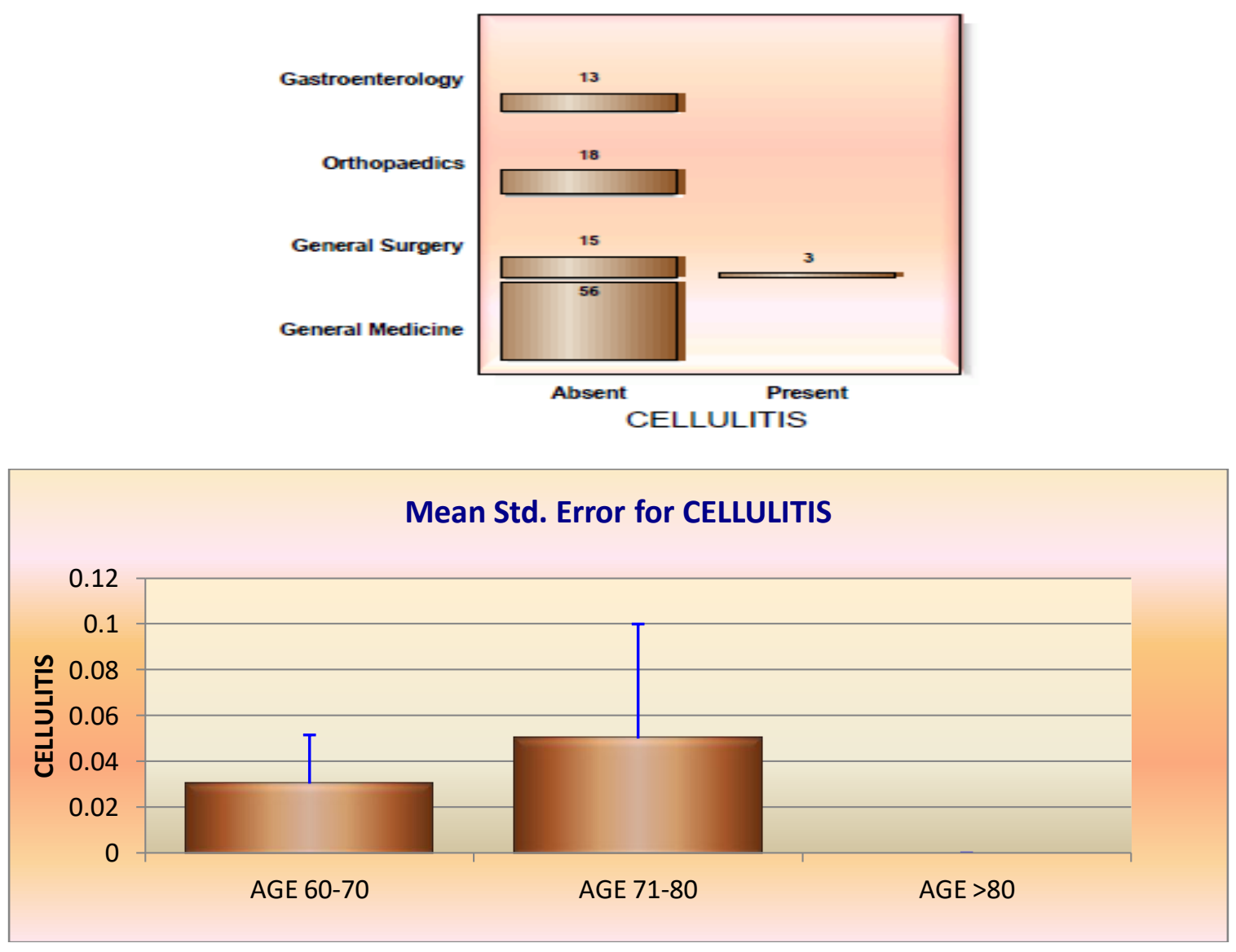
Surgery:-

\begin{tabular}{|l|l|c|c|c|l|}
\hline Source of variation & \multicolumn{1}{|c|}{ df } & Sum of squares & Mean Squares & F Ratio & Probability \\
\hline Between Samples & 3 & 5.35556 & 1.78519 & 17.666 & 0.00000 \\
\hline Within Samples & 101 & 10.20635 & 0.10105 & & \\
\hline
\end{tabular}

\section{Frequency Distribution}
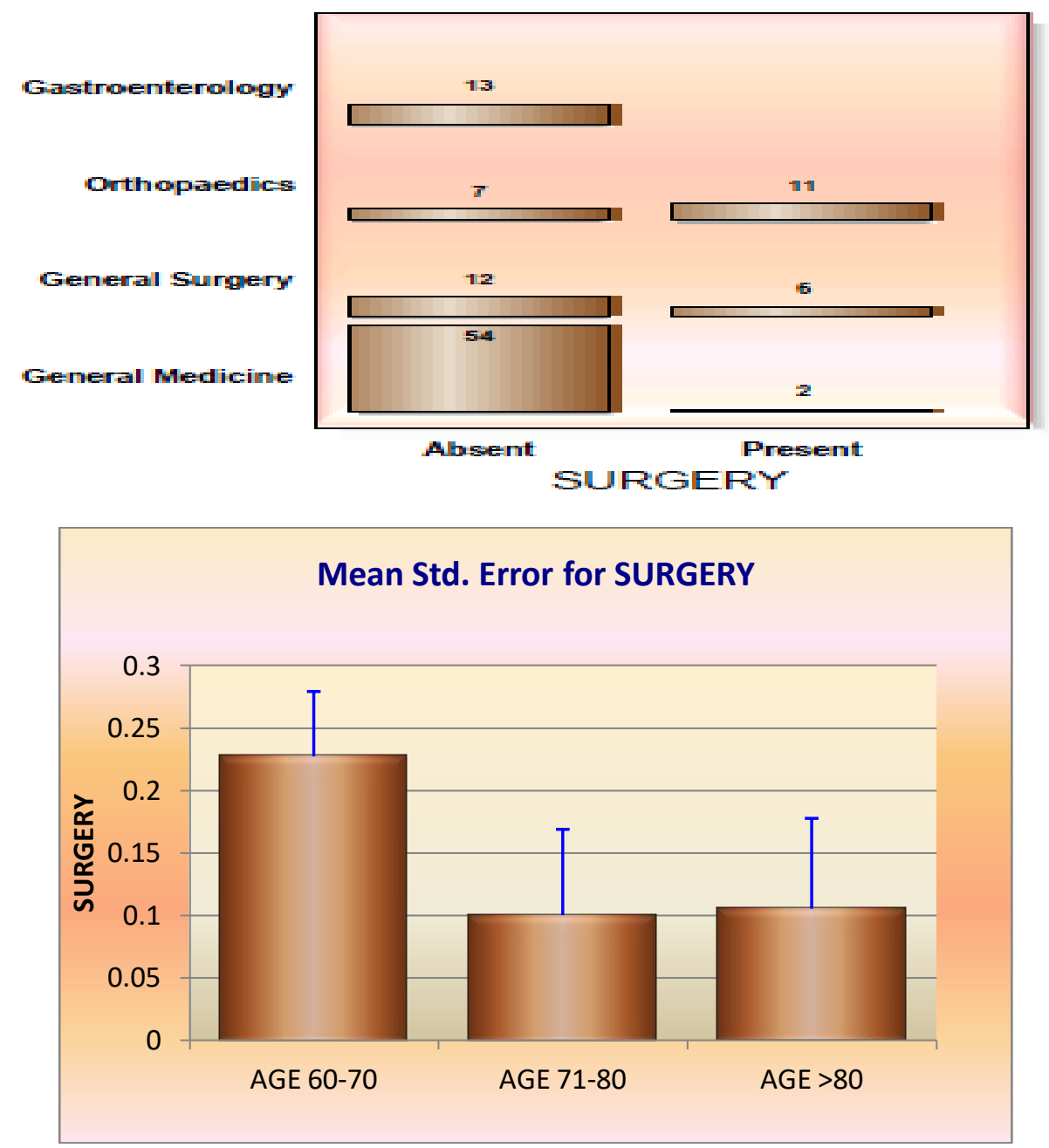

Peritonitis:-

\begin{tabular}{|l|l|c|c|c|l|}
\hline Source of variation & \multicolumn{1}{|c|}{ df } & Sum of squares & Mean Squares & F Ratio & Probability \\
\hline Between Samples & 3 & 0.27753 & 0.09251 & 3.544 & 0.01728 \\
\hline Within Samples & 101 & 2.63675 & 0.02611 & & \\
\hline
\end{tabular}




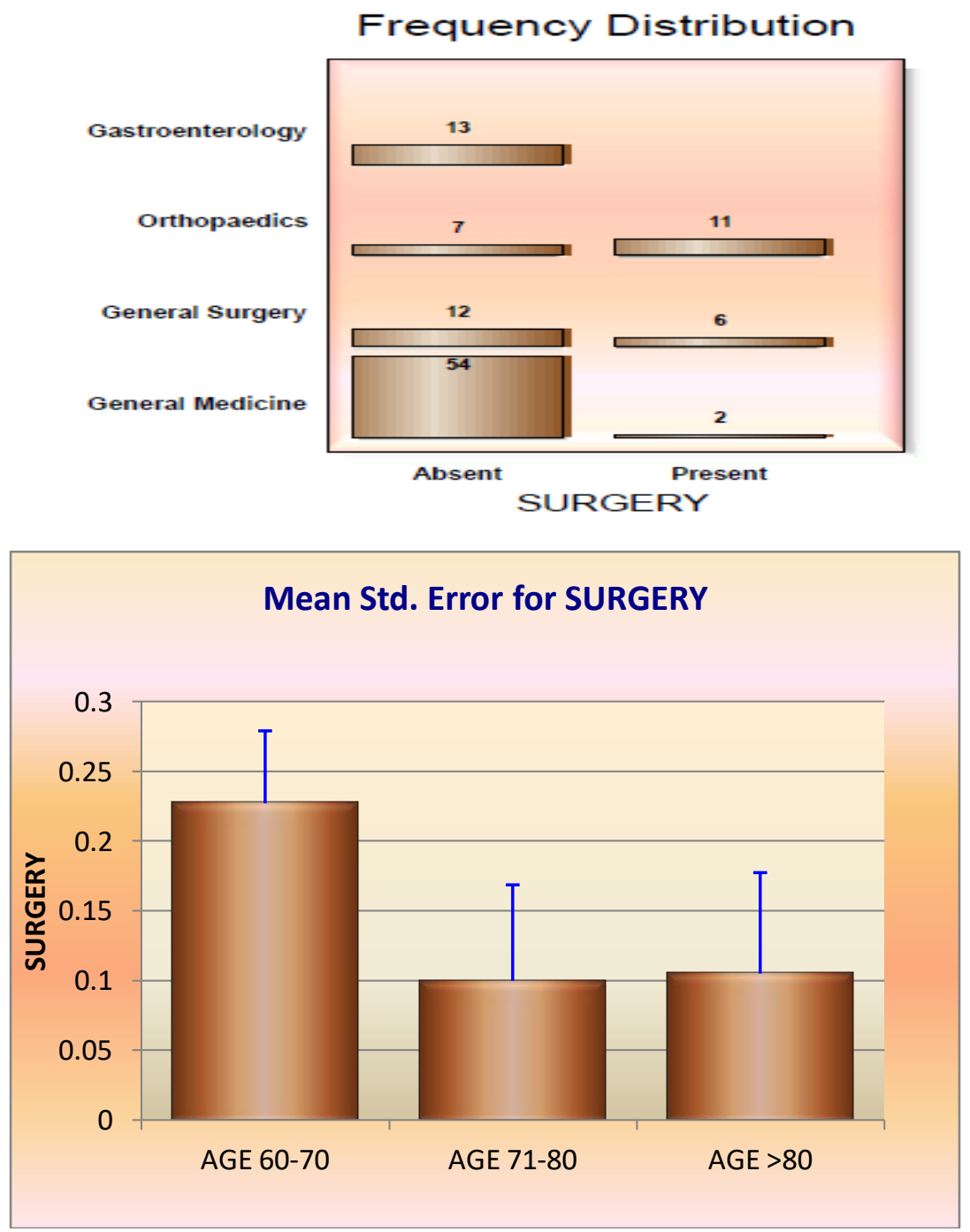

Minor Drug Interactions:-

\begin{tabular}{|l|l|l|c|c|l|}
\hline Source of variation & \multicolumn{1}{|c|}{ df } & Sum of squares & Mean Squares & F Ratio & Probability \\
\hline Between Samples & 2 & 0.243 & 0.121 & 0.409 & 0.666 \\
\hline Within Samples & 102 & 30.272 & 0.297 & & \\
\hline
\end{tabular}

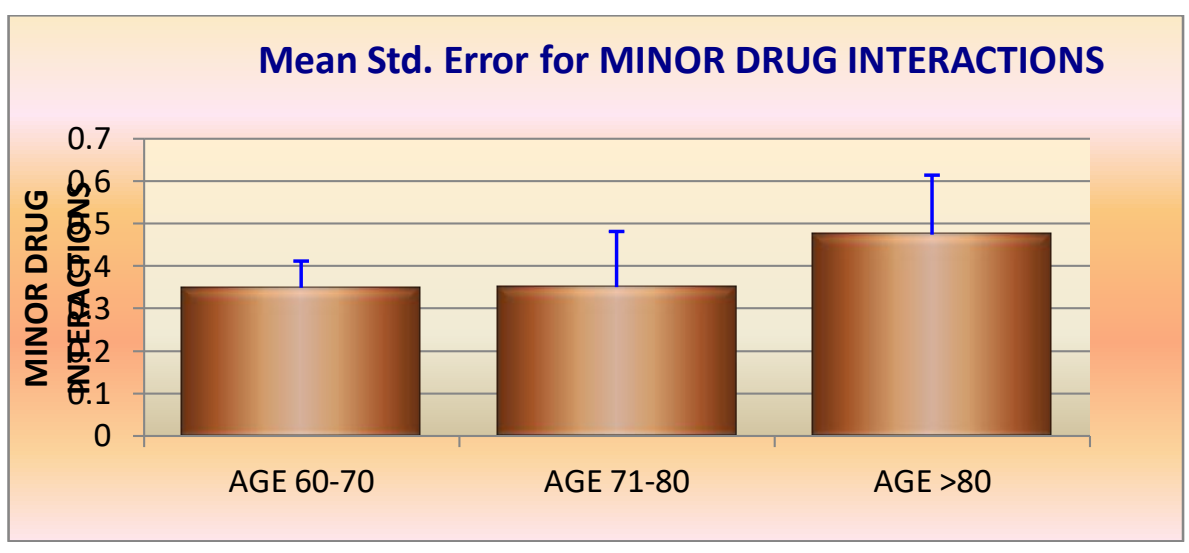


Moderate Drug Interactions

\begin{tabular}{|l|l|l|c|c|l|}
\hline Source of variation & \multicolumn{1}{|c|}{ df } & Sum of squares & Mean Squares & F Ratio & Probability \\
\hline Between Samples & 2 & 2.581 & 1.290 & 1.740 & 0.181 \\
\hline Within Samples & 102 & 0.742 & 0.000 & 0.000 & \\
\hline
\end{tabular}

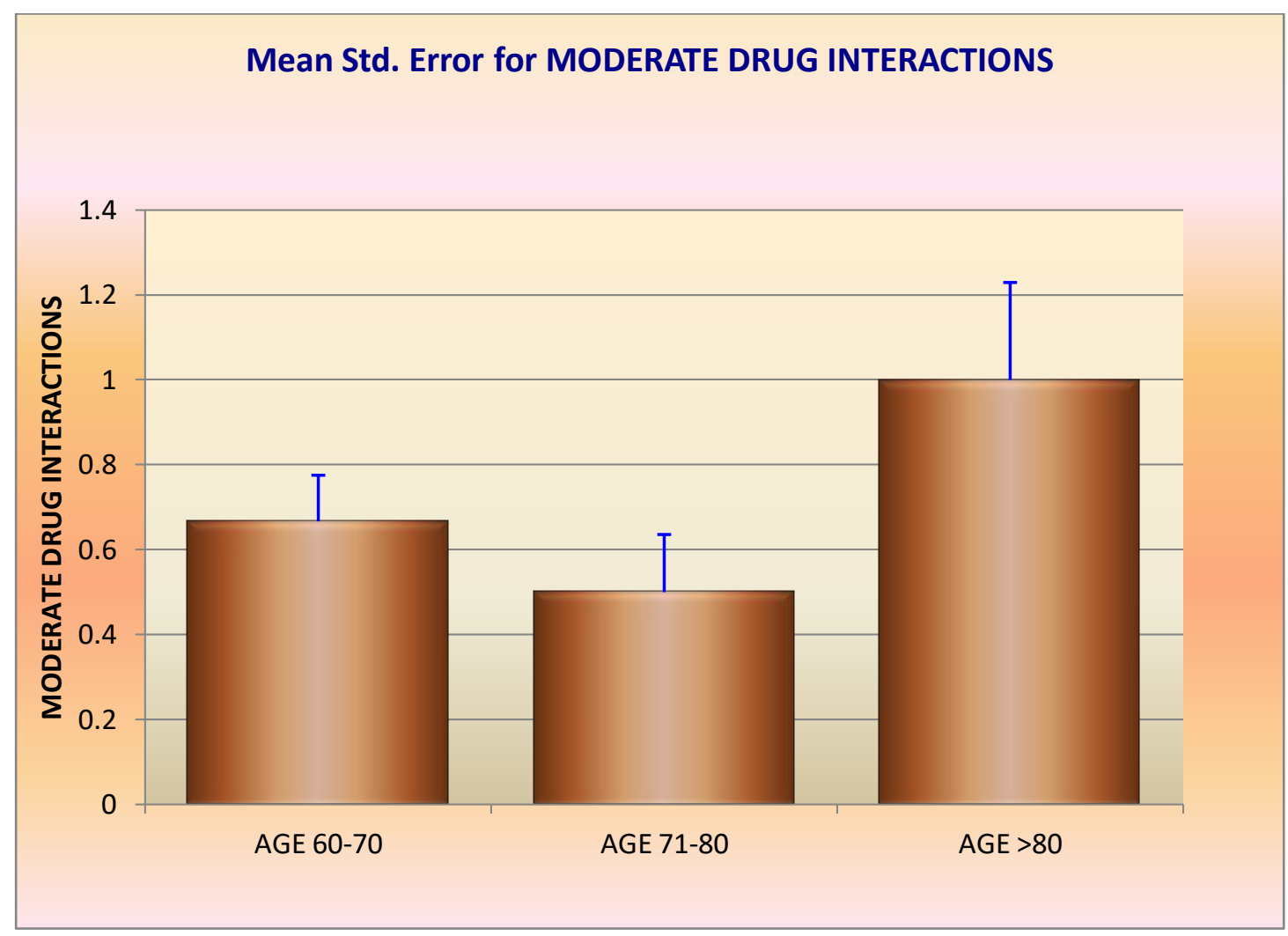

Moderate Drug Interactions:-

\begin{tabular}{|l|l|l|c|l|l|}
\hline Source of variation & \multicolumn{1}{|c|}{ df } & Sum of squares & Mean Squares & F Ratio & Probability \\
\hline Between Samples & 2 & 0.491 & 0.245 & 2.149 & 0.122 \\
\hline Within Samples & 102 & 11.643 & 0.114 & & \\
\hline
\end{tabular}




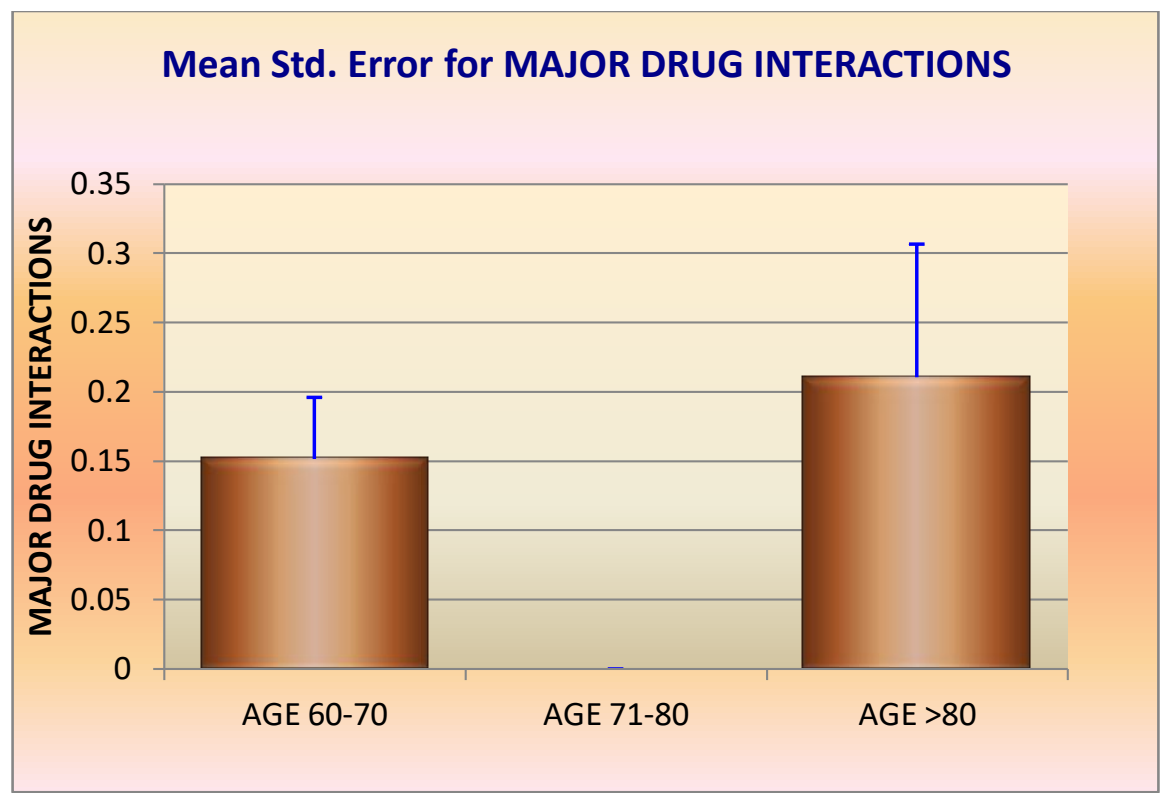

Aspirin:-

\begin{tabular}{|l|l|l|c|c|l|}
\hline Source of variation & \multicolumn{1}{|c|}{ df } & Sum of squares & Mean Squares & F Ratio & Probability \\
\hline Between Samples & 3 & 2.40317 & 0.80106 & 6.149 & 0.00070 \\
\hline Within Samples & 101 & 13.15873 & 0.13028 & & \\
\hline
\end{tabular}

Frequency Distribution

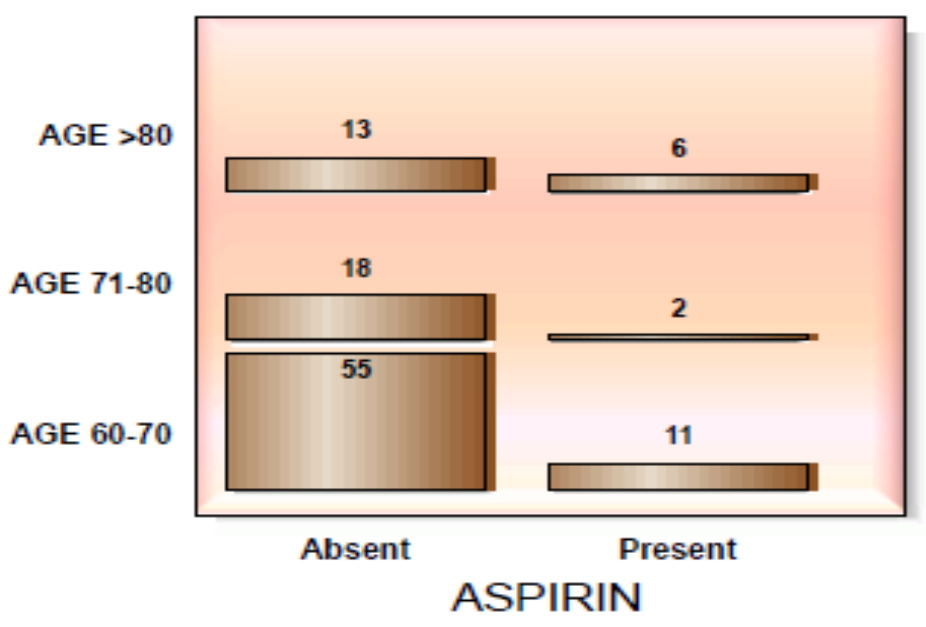




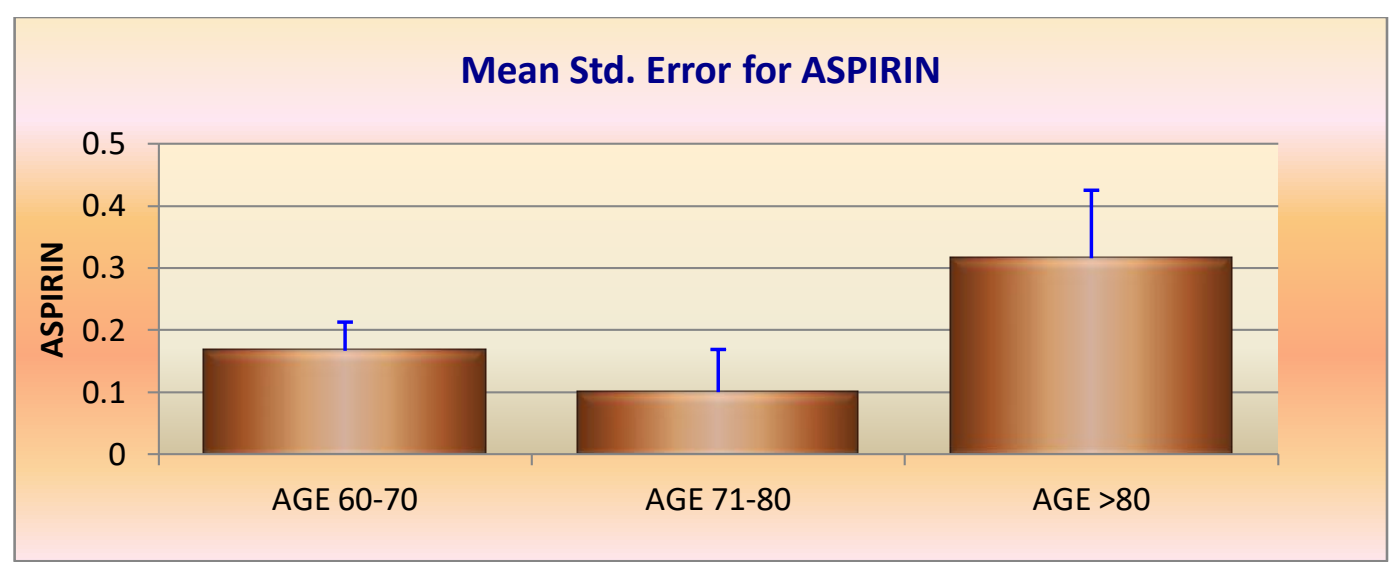

SPIRINOLACTONE

\begin{tabular}{|l|l|l|c|l|l|}
\hline Source of variation & \multicolumn{1}{|c|}{$\mathrm{df}$} & Sum of squares & Mean Squares & F Ratio & Probability \\
\hline Between Samples & 3 & 1.19649 & 0.39883 & 3.952 & 0.01038 \\
\hline Within Samples & 101 & 10.19399 & 0.10093 & & \\
\hline
\end{tabular}

\section{Frequency Distribution}

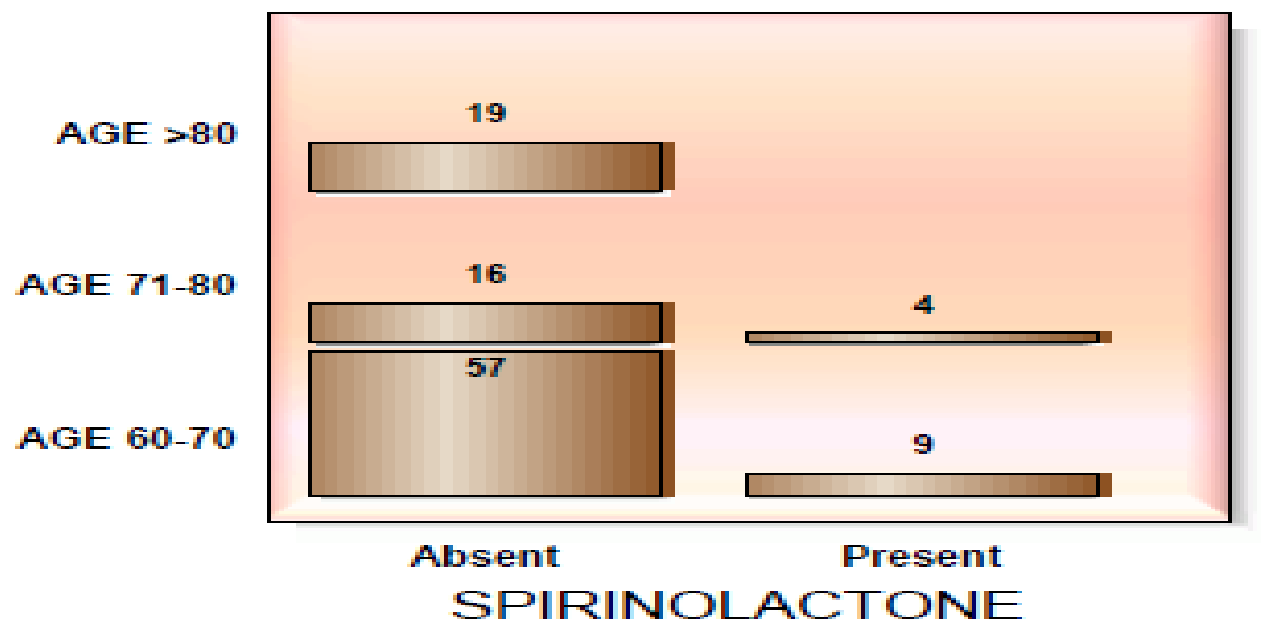




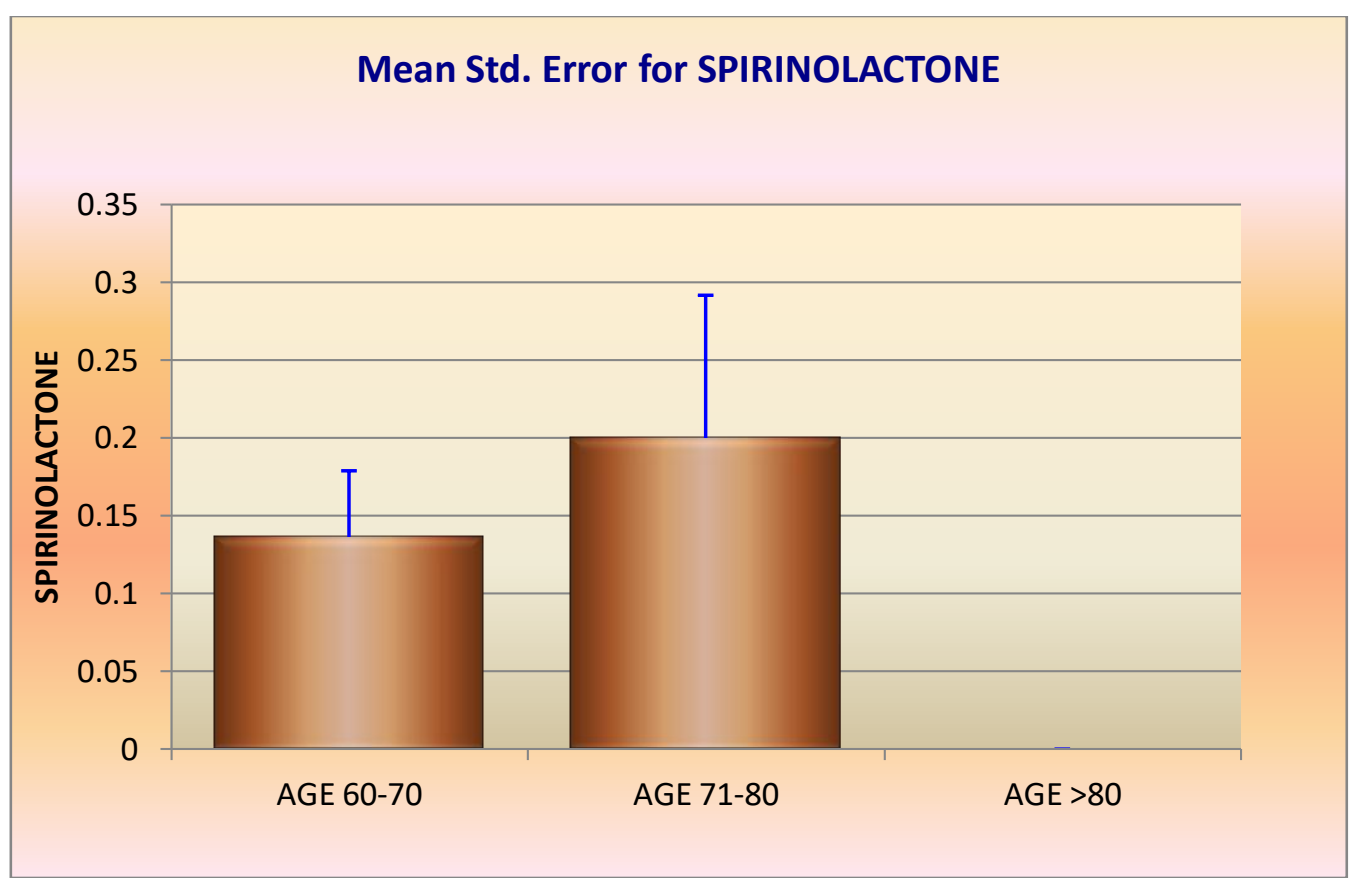

Diclofenac:-

\begin{tabular}{|l|l|c|c|c|l|}
\hline Source of variation & \multicolumn{1}{|c|}{ df } & Sum of squares & Mean Squares & F Ratio & Probability \\
\hline Between Samples & 3 & 0.61944 & 0.20648 & 4.140 & 0.00821 \\
\hline Within Samples & 101 & 5.03770 & 0.04988 & & \\
\hline
\end{tabular}

\section{Frequency Distribution}

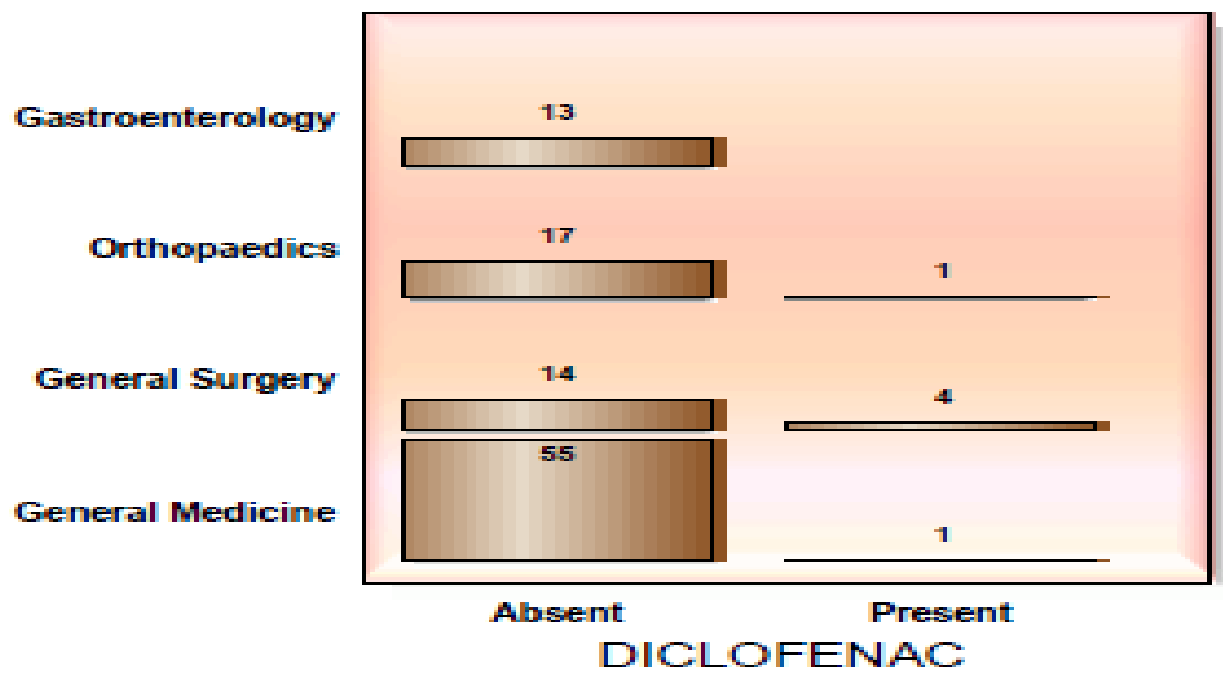




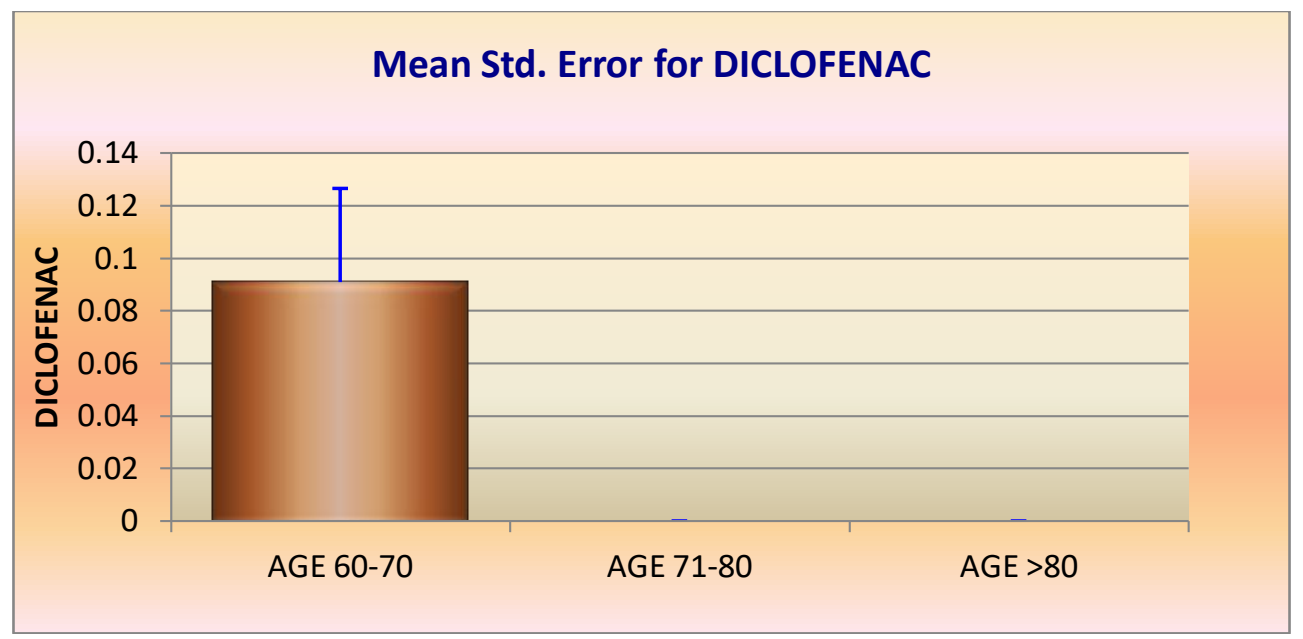

\section{Discussion:-}

1. 105 geriatric group were included to assess the use of polypharmacy in teritiary care hospital and was analysed by ANOVA and by using Windostat Version 9.2 from Windostat services.

2. Among 105 cases it was observed that $38 \%$ were female and $62 \%$ were male.

3. There was no significance difference in the departments included in the work such as General Medicine, General Surgery, Orthopaedics, Gasteroentreology.

4. Negar Golchinh et.al., conducted a study and concluded that there was no significant difference (age-0.16 and gender-0.32) between age and gender and in our study we observed age(P-value-0.072,gender-0.723).

5. Pantop (P-value- 0.028), Nicardipine (P-value-0.03) were inappropriate as per Beer's criteria and were significant in our study, which was similar to the study conducted by Md. Mamum Al-Amin et.al., RJ Lithe,M.Lankar et.al.

6. Mannitol was appropriate as per Beer's criteria included in our study (P-value-0.005) which was correlated to the study conducted by Chitra et.al.,

7. It was observed that inappropriate drugs as per our study are Aspirin(P-value-0.0007), Spironolactone(P-value0.010), Diclofenac(P-value-0.008), which was parellel to study conducted by Chitra et.al.,

8. Cardiovascular disease (P-value-0.01749) has shown significant difference in our study which was similar to study conducted by Md.Mamum Al-Amin et.al.,

9. Cerebrovascular accident (P-value- 0.0134) has shown significance in our study which was related to the study conducted by Kaite Gallacher,et.al.,

10. Surgery(P-Value 0.008) was found significant in our study which was corelated to the study conducted by Harstedt M,

11. Osteoarthritis (P-value0.001) has shown significant difference in our study which is parallel to the study conducted by John L Wallace

12. Diseases like Diabetic foot with $\mathrm{CAD}(\mathrm{P}$-value-0.018), Cholelithiasis(P-value-0.017),Cellulitis(P-value0.001),Peritoinitis(P-value-0.017), Traumatic quadripersis(P-value-0.017) has shown significant difference.

13. Consequences of polypharmacy like drug interactions has no significant difference(Minor-0.06, Moderate0.181,Major-0.122) which was similar to the study conducted by Akram Ahmad,,et.al.,

14. ADR's also have shown no significance difference of about 0.001 which was similar study conducted by James Wooten et.al.,

\section{Conclusion:-}

Polypharmacy and inappropriate drug use is prevalent among the elderly. In our study, Polypharmacy is involved more in cardiovascular diseases and surgery. Inappropriate drugs like aspirin, nifidipine, spironolactone, dicoflenac aresignificant. So, while prescribing drugs to elderly Beer's criteria and STOPP/START criteria should be considered as a standard guideline. 
To improve the medication adherence and to promote rationale therapy in geriatrics we recommend:-

1. Regular medication review.

2. Identify the drug interactions, common side effects.

3. Discourage the patients regarding the use of self-medication, over the counter medication and herbal medications or supplements.

4. Ensure that the dose, frequency, and route are appropriate.

5. Educate the patient and care giver regarding the safe medication use.

6. There is evidence that may Older adults receive medicaions that could potentially cause more harm than good.

7. Finding the right balance between too few and too many drugs will help to ensure increased longevity, improved overall health and enhanced functioning and quality of life for the aging population.

8. Many patients take their medications incorrectly and a large number receive prescriptions from more than one physician.

9. The physiologic changes that occur with aging, biotransformation and excretion (pharmacotinetics).

10. The use of medicines in a disease condition is necessary, but unnecessary load of drug to patient will Increase the safety Problems

11. Polypharmacy can be avoided by sharing treatment goals and plans. To improve drug safety in this high risk population.

\section{References:-}

1. Marlene Monegat, Catherine Sermet,MarccPerronin, Emeline Rococo. Polypharmacy :Definitions, Measurments and stakes involved in review of literature and measurment test 2014:volume-204:1-8 .

2. Kirsten VitkilK,Hege Salvesen Blix,AsmundReikvam . The Janus face of Polypharmacy - overuse versus underuse of medication. NorskEpidemologi 2008;Volume $18: 147-152$.

3. Chitra,SenthivelN,SowmyaR,Sreerekhasathyan,Srisha. A Study on prescribing pattern of drugs in geriatrics using beers criteria. International journal of pharmaceutical sciences and research2016; Volume 5.50:4810-4825

4. FitaRahmawati, DewaputuPramantara, WasilahRohmah, Syed Azhar Syed Sulaiman. Polypharmacy and unnessecsary drug thearpy on geriatric hospitalized patients. International journal of pharmacy and pharmacetical sciences 2009:volume-1:6-11 .www.researchgate.net. www.ncbi.nlm.nih.gov/pubmed. www.medscape.com .

5. Beers Criteria For Potentially Inappropriate Medications to used in caution with elderly. American Geriatric Society For Health in aging:1-16.

6. Edward K. Osei, Cristóbal S. Berry-Cabán, , Chelsey L. Haley, MSCR and Heather Rhodes-Pope.Prevalence of Beers criteria medications among elderly in a military hospital.US National library of medicine national institute of health 2016.

7. Hilary Hmilton,PaulGallagher,Cristian Ryan et.al.. Potentially inappropriate medications defined by the STOPP criteria and the risk of adverse drug events in the older hospitalised patients.Jama internal medicine 2011:volume 171(11):1013-1019.www.eldercareresorcespittsburgh.com www.pharmacy times.com

8. Emily HajjarR,AngelaCafieroC,Joseph Hanlon T.Polypharmacy in Elderly .The American Journal of Geriatric Pharmacotherapy 2007; Volume $5: 345-350$.

9. Ryan.C. STOPP and START ConsesusValidation.International Journal of Clinical Pharmacology and Therapeutics 2220: Volume $46: 72-83$.

10. Howard Fillit M et.al.,Polypharmacy Management in Medicare Managed Care : Changes in Prescribing by Primary Care Physicians Resulting from a Program Promoting Medication Reviews The American Journal of Managed Care 1999; Volume $5:$ 587-594.

11. Richard Grant W,NicoleDevitaG,Daniel Singer E,JamesMeiges B .Polypharmacy and Medication Adherence in Type 2 Diabetes patients .American Diabetes Association 2003;Volume 5: 1413-1420 .

12. Debbie Kwan,BarbaraFarell.Polypharmacy : Optimizing Medication Use in Elderly Patients. CGS Journal of CME 2014; Volume $4: 21-27$.

13. NeethuFathimaUmar,Juno Joel J, RaghavSharma,ShastryCS,RameshAdepu. Significant role of Clinical Pharmacist in the Assesment of Inappropriate Medications Prescribed to the Elderly patients in a University teaching Hospital. Asian Journal of Pharmaceutical and Clinical Research 2015; Volume $8: 109-112$.

14. MuktaChowta $\mathrm{N}$ et.al ., Evaluation of Appropriateness of Prescription and Polypharmacy in the Geriatric Population: A Cross sectional study at a Comprehensive Geriatric Clinic in a Tertiary Care Hospital.International Journal of Pharmacy and Pharmaceutical Sciences 2016; Volume 8 : 119-122 . 
15. SangharshilaBansetet.al .,Prescribing Pattern,Polypharmacy and Potentially Inappropriate Prescribing in hospitalized Elderly Patients : A Retrospective study in a teaching hospital in Nepal. International Journal of Scientific Reports Jan 2 2016; Volume 2: 7-12.

16. Shih-Wei Lai, et al., Polypahrmacy correlates with increased risk for hip fracture in the elderly.A population based study. www.md-journal.com, Sep 2010 volume 89.

17. Stewart.R.E, Meyboom-de jong B, Haaijer-Russkamp. Adverse drug reactions and polypahrmacy in the elderly in general practice: A retrospective crosssectional study in general practice. European journal of clinical pharmacy October 1999: 533-536.

18. Alessandro Nobili et al ., Polypahrmacy length of hospital stay and in-hospital mortality among elderly patients in internal medicine wards. A cross sectional study in internal medicine wards Italy. European journal of clinical pharmacology 2011: 507-519.

19. Ayesha Romana, Lakshmi kamath,AsthaSarda,SushmaMuraraiah. Polypharmacy leading to adverse drug reactions in elderly patients. A prospective observational study in tertiary care hospital. International journal of pharma and bio sciences July 2012: 218-224.

20. Debbie Lawlor A,Rita Patel, Shah Ebrahim. Association between falls in elderly women and chronic diseases and drug use.A cross sectional study. In British medical journal 27 September 2003 volume-327: 1-6

21. Arvind Nag K,Umesh.M, ShobhaChuri .Assessment of drug to drug interactions in hospitalized patients. A prospective study in hospitalized patients. In Asian journal of pharmaceutical and clinical research 2011 volume- 11: 62-65.

22. Negar Golchin, Scott H.Frank et.al., Polypharmacy in the elderly a cross sectional study Feb 2015 In Journal or research in pharmacy pratice.

23. Md. Mamum Al-Amin et.al., RJ Lithe,M.Lankar et.al ., Study on Polypahramcy in patients with Cardiovascluar diseases. December 2012 In Journal of applied pharmaceutical sciences vol.2 (12). 